\title{
A Survey of Modeling of Lattice Structures Fabricated by Additive Manufacturing
}

\author{
Guoying Dong, Yunlong Tang, Yaoyao Fiona Zhao' \\ Department of Mechanical Engineering, McGill University \\ 817 Sherbrooke Street West, Montreal, Quebec H3A 0C3 \\ Montreal, Canada
}

\begin{abstract}
The lattice structure is a type of cellular material with truss-like frames which can be optimized for specific loading conditions. The fabrication of its intricate architecture is restricted by traditional manufacturing technologies. However, Additive Manufacturing (AM) enables the fabrication of complex structures by aggregation of materials in a layerby-layer fashion, which has unlocked the potential of lattice structures. In the last decade, lattice structures have received considerable research attention focusing on the design, simulation and fabrication for AM techniques. And different modeling approaches have been proposed to predict the mechanical performance of lattice structures. This review introduces the aspects of modeling of lattice structures and the correlation between them; summarizes the existing modeling approaches for simulation; and discusses the strength and weakness in different simulation methods. This review also summarizes the characteristics of AM in manufacturing cellular materials and discusses their influence on the modeling of lattice structures.
\end{abstract}

Keyword: Additive Manufacturing, Finite Element Analysis, Homogenization, Lattice Structure

${ }^{1}$ Corresponding Author, E-mail: yaoyao.zhao@mcgill.ca 


\section{Introduction}

The word 'lattice' derives from old French 'latte' and it is defined as a structure consisting of strips of wood or metal crossed and fastened together with square or diamond-shaped spaces left between [1]. In this review, the lattice structure refers to a type of cellular materials [2] that has a truss-like structure with interconnected struts and nodes in a threedimensional (3D) space. Compared to other cellular materials such as random foams and honeycombs, the lattice structure exhibits better mechanical performance [3]. By tailoring the material, the lattice structure can be optimized to satisfy specific functional requirements, which means the mechanical properties are more flexible to be controlled.
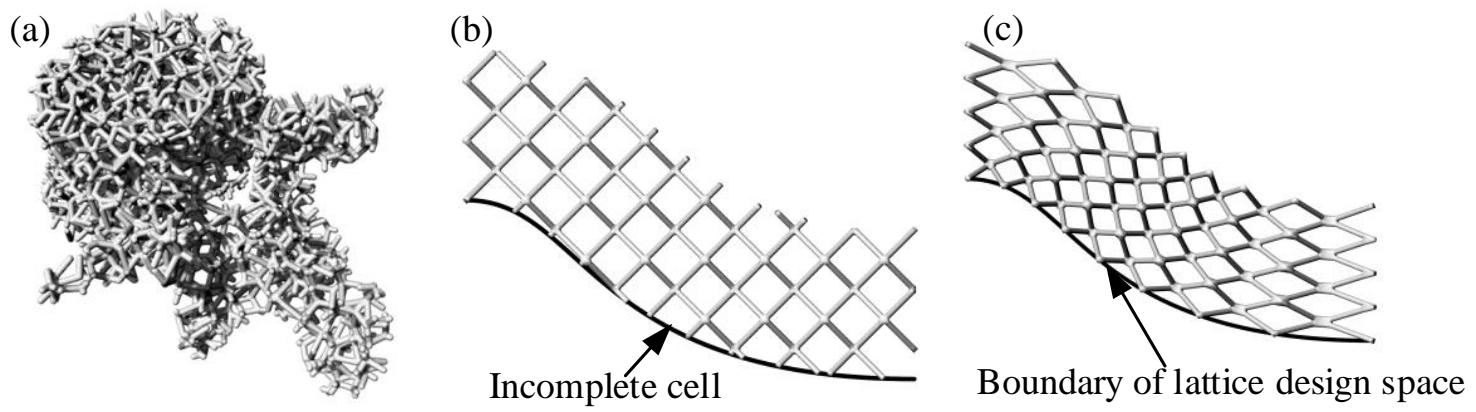

Figure 1. Examples of different types of lattice structures based on the degree of order, (a) Disordered lattice structures, (b) Periodic lattice structures, (c) Conformal lattice structures

According to literatures [4-6], there are more than one methods to classify the lattice structures. In this paper, lattice structures are categorized based on their degree of order of the lattice frame. Generally, they can be classified into three categories. The first type is called disordered lattice structures or randomized lattice structures. The unit cells of this type of lattice structures are randomly distributed inside the design space with different topologies and cell size. An example of disordered lattice structures is shown in Figure 1(a). The second type of lattice structures is called periodic lattice structure as shown in 
Figure 1(b). This type of lattice structures can be regarded as a structure created by a regular periodic repetition of a unit cell with certain shape, topology and size in a threedimensional Euclidean space. Thus, every cell in this type of lattice structures is in the same topology and size. Besides disordered lattice structures and periodic lattice structures, another type of cellular structure is called pseudo-periodic lattice structures. In this type of lattice structures, lattice cell only share the same topology but different size and shape. For example, the conformal lattice structure which is firstly proposed by Wang and Rosen [7] is a typical pseudo-periodic lattice structure. Conformal lattice structures are capable of keeping the integrity of their unit cells on the boundary as shown in Figure 1(c), which can stiffen or strengthen a complex and curved surface than periodic lattice structures $[8,9]$. Both the periodic and the pseudo-periodic lattice structures can be further divided into two sub-types based on the uniformity of strut's thickness. They are homogenous lattice structures and heterogenous lattice structures.

Due to tailorable properties, the periodic and pseudo-periodic lattice structures are more widely used in engineering applications. In most cases, the lattice structure is applied as lightweight core materials in a sandwich structure to transverse shear and compression loads. Compared to honeycombs, the lattice structure has the potential to improve compressive and shear strengths when designed to suppress buckling [10, 11]. Heterogeneous lattice structures with spatially graded density matched to the local loads can further save the weight of traditional cores with uniform density and properties. The lattice structures can also be used as energy-absorbing materials for protection from impact and shockwaves. Schaedler et al. [12] have investigated different types of metallic microlattice structures for energy absorber by quasi-static compression tests. It was shown 
that the lattice structure offers more flexibility in tailoring the response to impulsive loads than conventional materials can. Because lattice structures have high surface area-tovolume ratio, they are ideal materials for thermal management $[13,14]$. The periodic lattice cores have shown better cooling performance than textiles and foams by comparing various heat sink technologies [15]. Besides, the lattice structure can also be used as biocompatible materials to repair tissue, cartilage and bone. It has the flexibility to satisfy the patientspecific defect geometry and biological features as well as mechanical properties [16].

Lattice structures with sophisticated geometries are successfully fabricated by several manufacturing techniques. Among them, Additive Manufacturing (AM) is especially well suited for the fabrication of complex lattice structures. AM is defined as 'the process of joining materials to make objects from 3D model data, usually layer upon layer' [17]. Because AM does not require specialized tooling. Structures with complex geometries can be fabricated by AM without dramatically increasing the manufacturing cost. Lattice structures designed for engineering applications have been successfully fabricated by different types of AM techniques such as Stereolithography (SLA) [18], Fused Deposition Modeling (FDM) [19, 20], Binder Jetting(BJ) [21], Selective Laser Melting (SLM) [22], Selective Laser Sintering (SLS) [23], and Electron Beam Melting (EBM) [24, 25]. Schaedler and Carter [2] summarized and compared different types of AM for lattice structures with respect to the geometry, material, graded properties, feature size, application performance and production rate. AM techniques can also be combined with metal casting, which is called "Indirect AM Based Casting", to fabricate lattice structures [26]. Even though this technique takes more steps to fabricated lattice structures, it can remove several existing constraints on the AM process such as thermal residual stress, poor 
surface finish and limited material selection. Recently, ultralight metallic microlattices have been fabricated by depositing thin-film metallic materials on the AM produced polymer template which is subsequently removed by chemical etching [27]. Apart from AM, lattice structures can also be fabricated by traditional manufacturing methods. One type of 3D carbon fiber reinforced plastic (CFRP) lattice is assembled by 2D building blocks of [0/90] CFRP laminate with reversible snap-fit connectors [28]. 3D metallic and composite lattices can also be fabricated by weaving, braiding, and knitting fibers and wires. However, these approaches are only able to manufacture lattice structures with simple topology which limits the freedoms of design. AM is still the most ideal and prevalent way to manufacture lattice structures currently.

However, there are two reasons make it challenge to precisely predict the mechanical performance of lattice structures fabricated by AM process. Firstly, because of the intricate geometry of lattice structures, existing methods may not be suitable for the simulation of the mechanical performance in engineering applications. Both the computational cost and the accuracy need to be improved for the simulation process of lattice structures with complex geometries and properties. Secondly, the AM process has unique characteristics in the fabrication which affect the properties of lattice structures. Although AM has the capability of fabricating complex structures, currently, it still has limitations. Understanding those limitations and characteristics can help designers utilize AM processes to manufacture lattice structures and simulate their mechanical properties more effectively. 


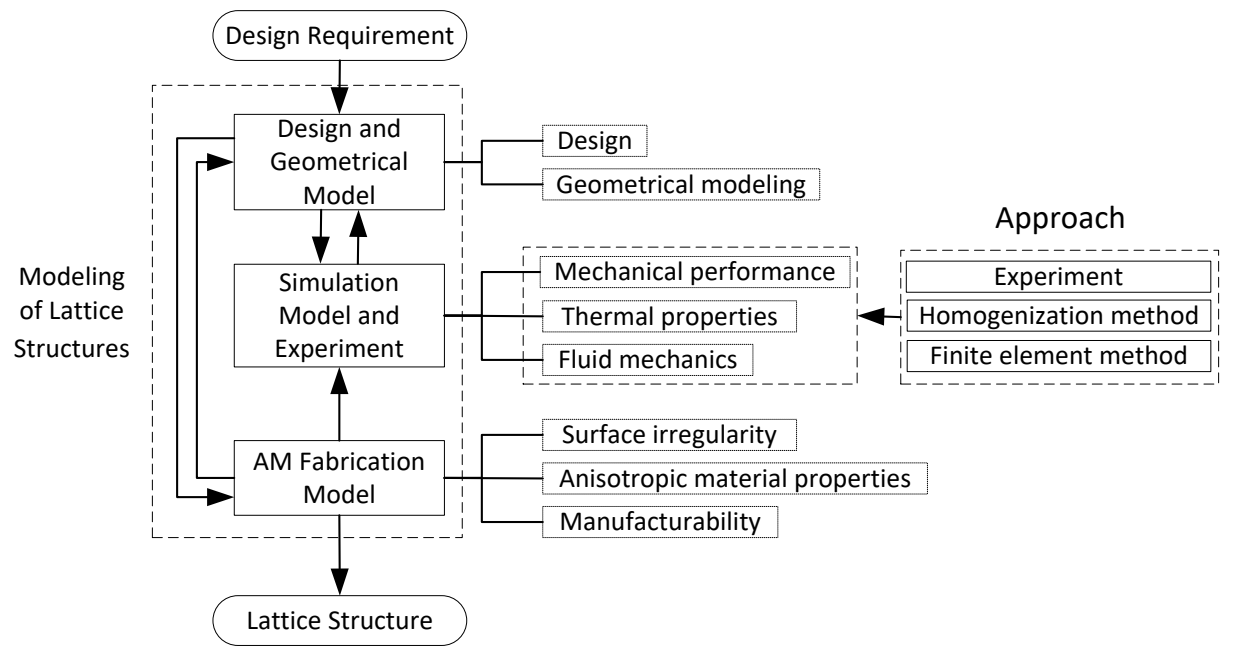

Figure 2. The concept of modeling of lattice structures for AM process

In this paper, a concept called modeling of lattice structures for AM is presented as shown in Figure 2. This concept is based on the design and fabrication methods for Additive Manufacturing proposed by Rosen [29], Yang et al [30], and Seepersad et al [31]. Rosen proposed a concept called Design for Additive Manufacturing (DFAM) that can support part modeling, process planning, and manufacturing simulations. This method includes the solution algorithms, analysis codes, libraries of materials and mesostructures, process planning and analysis of as-manufactured model. Yang et al proposed an approach that combines the analytical modeling, experimentation and simulation for the design of lattice structures. It is concluded that manufacturing factors are coupled with the actual cellular design, which need to be incorporated in to the geometric models to enable more accurate designs.

Based on existing theories, the concept in this paper is divided into three aspects: design and geometrical modeling; simulation modeling; and AM fabrication modeling. Based on functional requirements, the proper lattice structure is designed and generated. Then the 
design result is the geometrical input to the simulation modeling step. The simulation result then goes back to the geometrical modeling stage for the optimization of the initial design. The optimized geometrical model is the input to the AM fabrication modeling step. AM fabricated lattice structures need to be examined to check the manufacturability [32]. If it is not manufacturable, the geometrical model should be modified to remove unsuitable features for fabrication. Besides, the manufacturing process may have influence on the mechanical properties of lattice structures such as the irregular surface roughness and the anisotropic material properties, which also needs to be investigated. The influence of AM process should then be imported into the simulation model to improve the accuracy of the simulation result. When simulation results satisfy design requirements and the design model is manufacturable, the lattice structure can be fabricated, which finalize the modeling process.

This paper attempts to provide a comprehensive review of the state-of-the-art modeling approaches of lattice structures for researchers who aim to investigate the mechanical performance of lattice structures by experimental methods or simulations. In Section 2, experimental approaches as well as simulation modeling methods such as homogenization and Finite Element (FE) used in the investigation of mechanical performance of lattice structures will be discussed. Furthermore, manufacturing characteristics of AM have influence on the mechanical performance of lattice structures. These characteristics including surface irregularity and anisotropic material properties will be discussed in Section 3. Finally, these modeling methods are concluded and some future research to improve the existing modeling techniques of lattice structures are given in the last section. 


\section{Mechanical performance modeling}

The mechanical performance of cellular materials has been investigated for decades. In the early stage, restricted by the manufacturing techniques, only simple cellular structures were studied. Gibson et al. [33] investigated the mechanical properties of two dimensional cellular material with beam theory and compared the result with experimental data. The mechanical properties of 3D cellular materials were linked to the relative density $\rho / \rho_{s}$, where $\rho$ is the density of the cellular materials and $\rho_{s}$ is the density of the solid of which the structure is made. The relationships between linear elastic properties and the relative density for open-cell and closed-cell cellular material are given by [4, 34]

$$
\begin{gathered}
\mathrm{E} / \mathrm{E}_{s} \propto\left(\rho / \rho_{s}\right)^{2} \quad(\text { open cell }) \\
\mathrm{E} / \mathrm{E}_{s}=C_{1} \phi^{2}\left(\rho / \rho_{s}\right)^{2}+C_{1}^{\prime}(1-\phi)\left(\rho / \rho_{s}\right) \quad(\text { closed cell })
\end{gathered}
$$

Where $\mathrm{E}$ is the elastic modulus of the cellular material and $\mathrm{E}_{S}$ is the elastic modulus of the solid material of which the cellular material is made. $\phi$ is the fraction of solid in the cell edges. $C_{1}$ and $C_{1}^{\prime}$ are simply constants of proportionality. Other mechanical properties including elastic collapse, plastic collapse, creep, brittle crushing and fracture toughness were also correlated with the relative density [35]. Compressive experiments of cellular solids were conducted to get the stress-strain curve which was characterized by three regimes: a linear-elastic regime caused by elastic bending or stretching, a stress plateau caused by buckling, yielding or crushing, a densification caused by the load of the edges and cells against one another [36, 37].

The lattice structure is a type of cellular material which provides more flexibility to control the mechanical properties than the foam and honeycomb structures. Even though the 
relationship between the relative density and the mechanical performance of lattice structures can give designers a basic standard to choose the porosity of the lattice, it is difficult to precisely determine the mechanical performance of lattice structures only by the relative density. For instance, different topologies with the same porosity may have totally different mechanical properties such as the elastic modulus, shear modulus and Poisson's ratio. In order to predict the mechanical performance more accurately, the experiment, homogenization and FE methods are widely used to simulate lattice structures with different topologies. 
Table 1a A summary of compressive elastic modulus of lattice structures obtained from experiments

\begin{tabular}{|c|c|c|c|c|c|c|}
\hline $\begin{array}{l}\mathrm{AM} \\
\text { process }\end{array}$ & material & $\begin{array}{l}\text { Elastic } \\
\text { modulus of } \\
\text { bulk } \\
\text { material } \\
(\mathrm{GPa})\end{array}$ & $\begin{array}{l}\text { Lattice } \\
\text { topology }\end{array}$ & $\begin{array}{l}\text { Relative } \\
\text { density (\%) }\end{array}$ & $\begin{array}{l}\text { Compressive } \\
\text { Elastic modulus } \\
\text { (MPa) }\end{array}$ & Reference \\
\hline \multirow{14}{*}{ SLS } & \multirow{4}{*}{$\begin{array}{l}\text { polyamide } \\
\text { powder }\end{array}$} & \multirow{4}{*}{2.4} & 요 & \multirow{4}{*}{10} & 67.2 & \multirow{4}{*}[38]{} \\
\hline & & & & & 21.6 & \\
\hline & & & & & 40.8 & \\
\hline & & & & & 62.4 & \\
\hline & $\begin{array}{l}\text { Polycapro- } \\
\text { lactone } \\
\text { (PCL) }\end{array}$ & 0.1220 .013 & & $\begin{array}{l}45 \pm 0.9 \\
\sim 62.5 \pm 1.5\end{array}$ & $\begin{array}{l}54 \pm 3 \\
\sim 67 \pm 4\end{array}$ & [39] \\
\hline & \multirow{9}{*}{$\begin{array}{l}\text { polyamide } \\
\text { EOSINT } \\
\text { P/PA2200 }\end{array}$} & \multirow{9}{*}{$\begin{array}{l}1.419 \\
\pm 0.105\end{array}$} & & 20 & $49.67 \pm 9.93$ & \multirow{9}{*}[23]{} \\
\hline & & & & 40 & $163.19 \pm 1.42$ & \\
\hline & & & & 60 & $351.91 \pm 4.26$ & \\
\hline & & & & 20 & $509.42 \pm 4.26$ & \\
\hline & & & & 40 & $175.96 \pm 11.35$ & \\
\hline & & & & 60 & $378.87 \pm 49.67$ & \\
\hline & & & & 20 & $52.50 \pm 2.84$ & \\
\hline & & & & 40 & $153.25 \pm 8.51$ & \\
\hline & & & & 60 & $313.60 \pm 14.19$ & \\
\hline \multirow{3}{*}{ SLA } & \multirow{3}{*}{$\begin{array}{l}\text { RenShape }^{\mathrm{TM}} \\
\text { SL 7510 } \\
\text { resin } \\
\end{array}$} & \multirow{3}{*}{2.634} & $1 \times 1 \times 1$ octet & \multirow{3}{*}{35} & 107 & \multirow{3}{*}[40]{} \\
\hline & & & $2 \times 2 \times 2$ octet & & 60 & \\
\hline & & & $3 \times 3 \times 3$ octet & & 65 & \\
\hline FDM & $\begin{array}{l}\text { Polylactic } \\
\text { Acid }\end{array}$ & $\begin{array}{l}1684.87 \\
\pm 144.7\end{array}$ & & 7 & $49.07 \pm 0.13$ & [41] \\
\hline \multirow{2}{*}{ BJ } & \multirow{2}{*}{$\begin{array}{l}316 \mathrm{~L} \\
\text { stainless } \\
\text { steel }\end{array}$} & \multirow{2}{*}{4.07} & & 25.9 & 650 & \multirow{2}{*}{ [21] } \\
\hline & & & & 50 & 1480 & \\
\hline \multirow{11}{*}{ EBM } & \multirow{11}{*}{ Ti6Al4V } & 110 & & $5 \sim 11$ & $50 \sim 225$ & {$[42]$} \\
\hline & & \multirow{4}{*}{120} & & $50.25 \pm 1.00$ & $570 \pm 50$ & \multirow{4}{*}[25]{} \\
\hline & & & & $20.78 \pm 0.63$ & $2130 \pm 210$ & \\
\hline & & & & $39.59 \pm 0.81$ & $2680 \pm 120$ & \\
\hline & & & & $49.25 \pm 0.69$ & $2920 \pm 170$ & \\
\hline & & \multirow{6}{*}{114} & \multirow{3}{*}{$\begin{array}{l}\text { Octet as } \\
\text { built }\end{array}$} & 7.3 & 912 & \multirow{6}{*}{ [43] } \\
\hline & & & & 14 & 2041 & \\
\hline & & & & 28.5 & 6407 & \\
\hline & & & \multirow{3}{*}{$\begin{array}{l}\text { Octet } \\
\text { chemically } \\
\text { etched }\end{array}$} & 3.9 & 513 & \\
\hline & & & & 7 & 912 & \\
\hline & & & & 21 & 4560 & \\
\hline
\end{tabular}


Table 1b A summary of compressive elastic modulus of lattice structures obtained from experiments

\begin{tabular}{|c|c|c|c|c|c|c|}
\hline $\begin{array}{l}\text { AM } \\
\text { process }\end{array}$ & material & $\begin{array}{l}\text { Elastic } \\
\text { modulus of } \\
\text { bulk } \\
\text { material } \\
(\mathrm{GPa})\end{array}$ & $\begin{array}{l}\text { Lattice } \\
\text { topology }\end{array}$ & $\begin{array}{l}\text { Relative } \\
\text { density (\%) }\end{array}$ & $\begin{array}{l}\text { Compressive } \\
\text { Elastic modulus } \\
\text { (MPa) }\end{array}$ & Reference \\
\hline \multirow{27}{*}{ SLM } & \multirow{4}{*}{$\begin{array}{l}\text { Ti6Al4V- } \\
\text { ELI }\end{array}$} & \multirow{4}{*}{$\begin{array}{l}\text { Not } \\
\text { mentioned }\end{array}$} & \multirow{4}{*}{$\begin{array}{l}\text { rhombic } \\
\text { dodeca- } \\
\text { hedron unit } \\
\text { cells }\end{array}$} & 16 & $549 \pm 76$ & \multirow{4}{*}{ [44] } \\
\hline & & & & 22 & $1397 \pm 115$ & \\
\hline & & & & 30 & $2619 \pm 64$ & \\
\hline & & & & 33 & $3488 \pm 137$ & \\
\hline & \multirow{9}{*}{$\begin{array}{l}316 \mathrm{~L} \\
\text { stainless } \\
\text { steel }\end{array}$} & \multirow{8}{*}{140} & & 3.5 & 10.6 & \multirow{8}{*}[45]{} \\
\hline & & & & 5.4 & 19.8 & \\
\hline & & & & 9.7 & 105 & \\
\hline & & & & 13.9 & 207.5 & \\
\hline & & & & 4.0 & 84.6 & \\
\hline & & & & 6.2 & 804.9 & \\
\hline & & & & 11.1 & 1506.2 & \\
\hline & & & & 15.9 & 2273.2 & \\
\hline & & $\begin{array}{l}97 \pm 10 \\
\text { (Micro } \\
\text { strut) }\end{array}$ & & $3.5-13.8$ & $17.646 \sim 378$ & [46] \\
\hline & \multirow{3}{*}{ CoCr alloy } & \multirow{3}{*}{200} & & 20 & 4143 & \multirow{3}{*}{ [47] } \\
\hline & & & & 30 & 6260 & \\
\hline & & & & 40 & 9844 & \\
\hline & AlSi10Mg & 72.4 & & 10 & 177.89 198.39 & [48] \\
\hline & \multirow{10}{*}{ Ti6Al4V } & \multirow[b]{2}{*}{110} & & & $\begin{array}{l}130 \pm 20 \\
\sim 1250 \pm 40\end{array}$ & \multirow[b]{2}{*}{ [49] } \\
\hline & & & & $5-20$ & $\begin{array}{l}120 \pm 30 \\
\sim 1250 \pm 70\end{array}$ & \\
\hline & & \multirow{8}{*}{114} & & 25 & $1900 \pm 100$ & \multirow{8}{*}{ [50] } \\
\hline & & & & 30 & $900 \pm 100$ & \\
\hline & & & & 40 & $3100 \pm 400$ & \\
\hline & & & & 50 & $4300 \pm 100$ & \\
\hline & & & & 25 & $1200 \pm 400$ & \\
\hline & & & & 30 & $1400 \pm 200$ & \\
\hline & & & & 40 & $3400 \pm 300$ & \\
\hline & & & & 50 & $4600 \pm 200$ & \\
\hline
\end{tabular}

\subsection{Experimental Method}

Experimental method is the most direct way to get the mechanical properties of asfabricated lattice structures. In the last decade, a number of experiments such as compression [51], bending [52] and tensile [53] tests, impact loading tests [54], dynamic 
tests [55], and fatigue test [56] have been done to investigate the performance of lattice structures fabricated by different types of $\mathrm{AM}$ techniques. The compressive elastic modulus of lattice structures obtained from experimental methods are summarized in Table 1.

It has been shown by lots of experiments that the mechanical properties of lattice structures fabricated via AM cannot be simply determined by the relative density. Many researchers found that the compressive modulus of lattice structures is related to the strut dimension, the cell size and the surface roughness as well. Parthasarathy et al. [25] studied the strength of Ti6Al4V cube lattice structure made by EBM with porosities ranging from $49.75 \%$ to $70.32 \%$. It is found that for nearly same porosities $(49.75 \%$ and $50.75 \%)$ with different strut thickness, the compressive modulus of the lattice structure decreased dramatically from $2.92 \mathrm{GPa}$ to $0.57 \mathrm{GPa}$, which indicates that the strength of the lattice structure depends not only on the porosity of the structure, but also on the geometrical dimension of the lattice strut. Similar results were found by Yan et al. [48, 57]. They conducted compressive experiment on the AlSi10Mg diamond lattice structure fabricated by SLM. The result showed that with the same volume fraction, the compressive strength was decreasing with the increase of the size of the unit cell. This can be explained by the "effective volume ratio" of the lattice strut that is proposed by Suard et al. [58]. Because the surface roughness of the strut fabricated by EBM is high, which has more influence on the mechanical properties of the thinner strut. Formanoir et al. [43] investigated the influence of the chemical etching on the mechanical properties of EBM fabricated Ti-6Al-4V octet-truss lattice structures by compression tests. The result showed that with the same relative 
density, the lattice structure after the chemical etching had a higher stiffness than the asbuilt structure due to the decrease in the surface roughness.

It is also found by experiments that many types of defects are likely to occur in AM fabricated lattice structures such as the irregular strut size, internal porosity and surface breaking defects. Qiu et al. [59] used optical microscopy (OM), scanning electron microscopy (SEM) and micro-CT to investigate the as-fabricated strut size, morphology and internal porosity of AlSi10Mg diamond lattice structures fabricated by SLM and correlate them with the compressive properties. The primary conclusion is that the diameter of the strut increase monotonically with laser power, which improves the compressive properties, but deviated from the designed geometry. The defects of the Ti6Al4V cube lattice structure fabricated by EBM process have also been studied to understand their effects on the mechanical response [60]. The result shows that the compressive yield strength was not affected much by the horizontal struts even though there are large surface breaking defects in them. Because the load direction is along the vertical struts which means the horizontal struts are redundant. However, the load direction along the horizontal struts is not discussed in this literature. The influence of the surface defect on the compressive yield strength still needs to be investigated.

Even though the experimental method can directly obtain the mechanical properties of lattice structures fabricated via different $\mathrm{AM}$ techniques with different geometrical characteristics, there are some obvious limitations to implement the experimental method in engineering applications. Since the fabrication cost of AM techniques is still high, the experimental method requires a certain amount of samples to minimize the error and improve the experimental accuracy, which is not economical for AM processes. Secondly, 
the speed of the manufacturing process of AM is relatively slow. It could take hours or days to fabricate a component via most of AM techniques. If a new lattice structure design needs to be verified for its mechanical performance, the experimental method is timeconsuming which may delay the whole design process. Thirdly, in the conceptual design level, a comprehensive database is required to select the appropriate topology and relative density. It is not applicable to construct such a database by experimental method due to the cost of the time and money. Finally, to further improve the mechanical properties of lattice structures in engineering applications, the optimization process is vital at the design stage, which may need many rounds of iterations to find the optimal design. The experimental method is impractical to optimize the mechanical performance of the lattice structure. Therefore, it is imperative to simulate the mechanical properties of lattice structures analytically and numerically. Two modeling methods have been widely investigated and applied to estimate the mechanical response of lattice structures, which are the homogenization method and the Finite Element (FE) method.

\subsection{Homogenization Method}

The homogenization usually refers to a way to replace the composite with a kind of equivalent material model, which can overcome the difficulty in the analysis of the boundary value problem with high heterogeneities [61]. The mathematical theory of homogenization has developed in the 1970s [62, 63]. It is used to obtain the effective properties of homogenized material for periodic heterogeneous continuous media in many physical and engineering applications. It can be divided into two steps. Firstly, the local problem based on a unit cell is solved to get the effective material properties. Secondly, the overall problem is solved by substituting periodic material to the homogenised material 
with equivalent properties. Compared with FE methods, the homogenization method can save much computational cost. As shown in Figure 3, the beam FE model comprises of 240000 elements while the solid FE model comprises only 1000 elements. Therefore, a radical reduction of the solution time and cost is achieved by application of the homogenised FE model [64, 65].
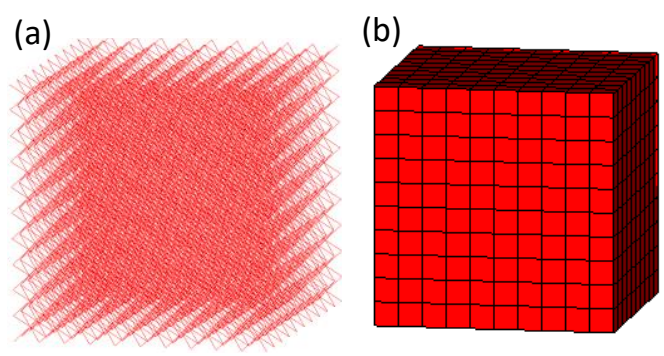

Figure 3. (a) FE model with beam elements, (b) Homogenized FE model with solid elements

The mechanical properties of lattice structures can be analysed by the homogenization method because it is a periodic structure constructed by unit cells. Based on an asymptotic expansion using periodicity, a homogenization approach with a solid model of lattice structures was developed. This approach is implemented to get the effective elastic modulus for a given unit cell. It can also be used in a design procedure to find the optimal topology of a unit cell under a certain boundary condition [66]. Rabczuk et al [67] implemented the homogenization method to represent the core cell of the impulsive load bearing sandwich panel by a continuum constitutive model with the consideration of buckling. The homogenized model was derived from the core cell by making the continuum-stored energy density function equal to a discrete energy associated to a representative core cell. This approach was more computational efficient to the fully discrete models yet results of both models showed very good agreement. Florence and Sab $[68,69]$ investigated the overall ultimate strength of general elastoplastic periodic $2 \mathrm{D}$ and 
3D lattice by using a rigorous homogenization method to solve unit cell problems with finite number of degrees of freedom. The method is restricted to the determination of overall linear elasticity constants and overall ultimate failure envelopes. The advantage of this method is that the non-uniform cell wall thickness and the non-symmetric material distribution in the cell edges can be considered in this method. Arabnejad and Pasini [70] investigated the mechanical properties of 6 different lattice topologies for a whole range of relative density by asymptotic homogenization.

Also, discrete homogenization approaches are widely used to simulate the mechanical properties of periodic lattice structures by using structural elements such as a truss element and a beam element. Tollenaere and Caillerie [71] applied the discrete homogenization method to model the quasi-repetitive lattice structures. The constitutive relation of their equivalent continuum was obtained by utilizing truss elements and pin-jointed nodes. This approach was also used to construct the equivalent macroscopic model for periodic structures such as graphene sheets which can be considered as lattices consisting of atoms and of interatomic bonds [72]. Reis and Ganghoffer [73] improved the discrete homogenization method by applying beam lattices instead of truss lattices. They used this approach to investigate the equivalent mechanical properties of auxetic lattices with two main mechanisms: the re-entrant and the rolling-up mechanism [74]. Because the predicted homogenized properties depend on the slenderness of the beam, and none of the simplifying assumptions are made, it provides more accurate results than those of Gibson and Ashby [36]. To investigate the large deformations of extensible beams and lattice structures, a heuristic homogenization technique was proposed by considering a discrete spring model to formulate a continuum fully nonlinear beam model [75]. Recently a new 
homogenization approach using semi-rigid joint frame element shown in Figure 4(a) and as-fabricated model shown in Figure 4(b) for periodic lattice structures was presented in order to incorporate the geometrical discrepancies obtained during the AM process [76]. In this literature, three homogenization approaches were implemented to get the normalized elastic modulus; the proposed approach, the discrete homogenization with conventional frame elements, and the asymptotic homogenization. Two types of lattice structures, the cubic cell lattice and the diamond lattice were investigated by these three methods. The simulation results were compared to experimental result. The discrete homogenization with conventional beams lead more errors than the proposed method. Furthermore, the asymptotic approach yields large error in cubic cell specimens, but it gives relative accurate estimates in diamond unit specimens. The proposed method can estimate the modulus more accurately for both type of lattice structures. These results showed that the geometrical degradation during the AM process has significant impacts on mechanical properties of lattice structures and the proposed method enables accurate estimations of mechanical properties of the as-fabricated samples.
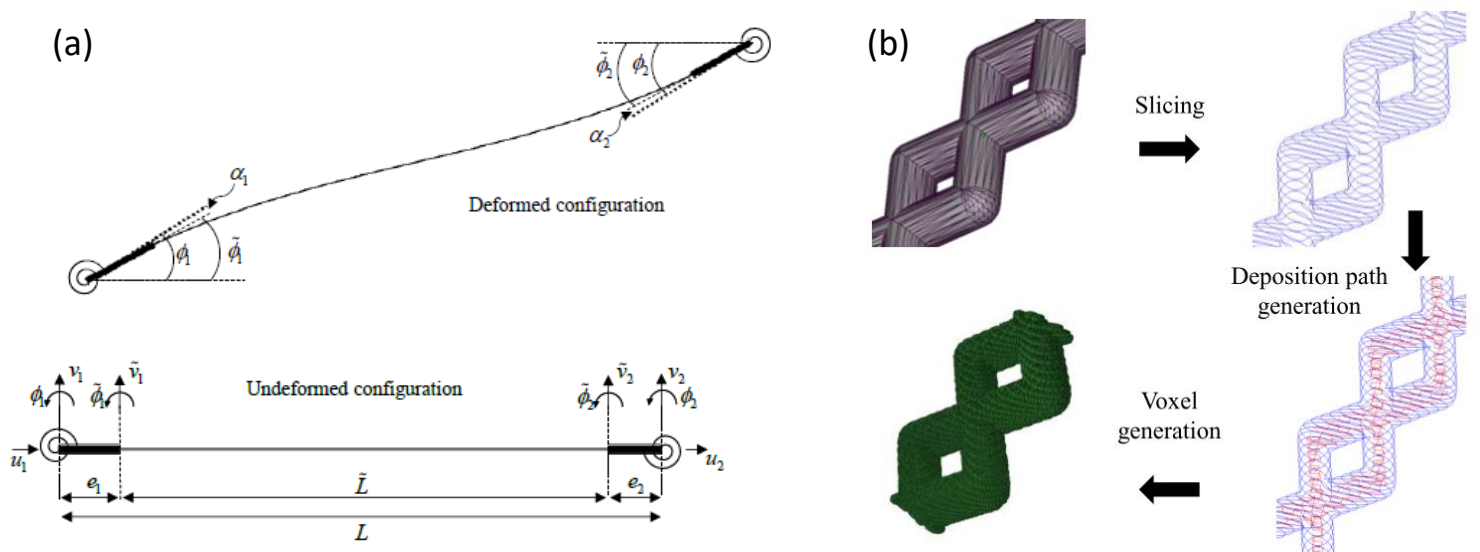

Figure 4. (a) the conceptual configuration semi-joint frame element (b) the as-fabricated voxel modeling procedure [76] 
In biomechanics, Assidi et al. [77] implemented the discrete asymptotic homogenization method to calculate the mechanical properties of biological membranes with lattice configurations. The effective moduli are calculated and recorded versus the geometrical and mechanical lattice parameters. Goda et al. [78, 79] proposed a quasi periodical lattice model of the cancellous bone which was discretely homogenized to generate the continuum model. The effective mechanical properties of the bone directly relate to the lattice microgeometry and micromechanical elastic properties. To evaluate fracture of trabecular bone, the overall plastic yield and brittle failure behaviors of three dimensional lattices are investigated by a microstructural modeling approach based on the homogenization of the initially discrete microstructure [80].

Matrix methods of linear algebra have also been used to homogenize the structural mechanics of periodic lattices. Hutchinson and Fleck [81] applied Bloch's theorem in the matrix analysis and formulated a homogenized stiffness matrix by expressing the nodal deformation in a unit cell in terms of the macroscopic strain. This methodology is applied to the collapse mechanisms of Kagome and triangular-triangular lattice structures. Vigliotti and Pasini [82] developed a general matrix-based homogenization approach for the linear analysis of components made of two dimensional lattice materials with either pin joints or rigid joints. A linear multiscale procedure has been described and validated by comparing the homogenized model of equivalent macroscopic stiffness with the discrete lattice model. The result has illustrated that the homogenised model delivered a correct estimation of the stiffness of the lattice. This procedure is successfully extended to 3D lattice structures [83] and the non-linear constitutive models for lattice structures [84]. Then, in order to consider the manufacturing influence of AM on the effective mechanical performance of lattice 
structures, a two-step homogenization method [85] was proposed based on the approach proposed by Vigliotti and Pasini [83]. In the first step, a voxel-based model was used to determine the effective structural element parameters by including the shape deviations in fabricated struts. Then the structural element parameter obtained by the voxel-based model was imported into the homogenization method to compute the mechanical properties. Compared with the experiment, the result estimated by the two-step approach showed less error than the direct homogenization method, which means that it is important to consider the shape variation caused by the manufacturing process.

Numerical homogenization is an alternative homogenization method to determine effective mechanical properties over a unit-cell with periodic boundary conditions using Finite Element Analysis (FEA). The educational description of this method has been provided based on a short Matlab implementation by Andreassen [86]. It is initially aimed to determine composite material properties, but single-phase lattice structures can be simulated by assigning a very soft second materials. This approach can be easily extended to the homogenization of conductivity, thermal expansion and fluid permeability. Dirrenberger et al. [87] used the numerical homogenization technique combined with FEA to compute the elastic moduli tensor and investigate the anisotropy of three auxetic periodic lattices. Van Dijk [88] presented an approach in the geometrically nonlinear regime for stress or strain driven homogenization which is straightforward in combination with FEA. Schwerdtfeger et al. [89] used a standard FEA in conjunction with a well known pseudo density approach to homogenize the linear elastic stiffness tensor of lattice structures with negative Poisson's ratio. It is found that the Poisson's ratio is strongly dependent on the relative density. Even though the numerical homogenization easier to be implemented, 
when the unit cell of the structure is relatively complicated, the computational cost could be considerable.

\subsection{Finite Element Analysis}

The development of AM technology provides more freedom for designers to create lattice structures with complex geometries and versatile functions, whose properties could be difficult to simulate with homogenization methods. Instead, Finite Element Analysis (FEA) has the capability of estimating the mechanical performance of complex structures. Recently, FE modeling of lattice structures has attracted plenty of attention from researchers and has been implemented to investigate the mechanical performance of lattice structures. Generally, FE modeling of lattice structures is constructed by beam elements or 3D solid elements as shown in Figure 5. It can be seen that the computation time of beam elements model is much less than that of the 3D solid mesh model because the quantity of beam elements is less than $1 \%$ of the quantity of $3 \mathrm{D}$ elements for the same structure. But in some cases, the lattice struct cannot be modeled by beam elements. 3D solid elements have to be applied to construct the FE model. To more clearly compare the methods that investigate the mechanical properties of lattice structures, both the advantages and disadvantages of experimental and simulation methods are summarized in Table 2. In this subsection, the applications of FE modeling techniques to investigate the mechanical properties of lattice structures will be discussed in detail. 
(a)

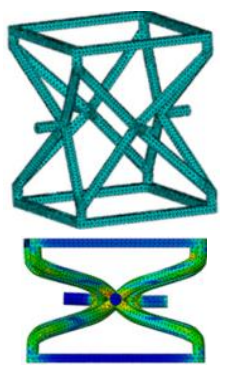

(b)

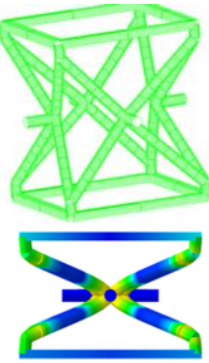

(c)

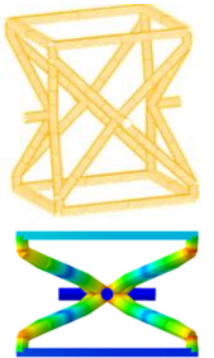

Figure 5. 3D tetrahedral elements compared with beam elements, (a) 3D solid mesh using 19830 elements and $2 \mathrm{~h} 44 \mathrm{mins}$ computational time, (b) $1 \mathrm{D}$ beam mesh using 160 elements and 51s computational time, (c) 1D beam mesh using 96 elements and 12s computational time.

Table 2 Advantages and disadvantages of experimental and simulation methods

\begin{tabular}{|c|c|c|}
\hline & Advantages & Disadvantages \\
\hline $\begin{array}{l}\text { Experimental } \\
\text { Method }\end{array}$ & $\begin{array}{l}\text { - It reflects the as-fabricated } \\
\text { mechanical properties } \\
\text { - It can be used as benchmarks } \\
\text { to verify the simulation } \\
\text { result }\end{array}$ & $\begin{array}{l}\text { - High cost of the } \\
\text { manufacturing process } \\
\text { - It is difficult to test functional } \\
\text { components with complex } \\
\text { shapes by standard testing } \\
\text { machine }\end{array}$ \\
\hline $\begin{array}{l}\text { Homogenization } \\
\text { Method }\end{array}$ & $\begin{array}{l}\text { - Low computational cost } \\
\text { - It can be used in Lattice- } \\
\text { Solid hybrid materials to } \\
\text { represent lattice structure }\end{array}$ & $\begin{array}{l}\text { - It is not applicable to } \\
\text { heterogeneous lattice } \\
\text { structures } \\
\text { - It is not easy to incorporate the } \\
\text { manufacturing defects } \\
\text { - It is mathematically difficult to } \\
\text { implement on a new topology }\end{array}$ \\
\hline $\begin{array}{l}\text { FE Model with } \\
\text { Beam Elements }\end{array}$ & $\begin{array}{l}\text { - Relatively low } \\
\text { computational cost } \\
\text { - It can model heterogeneous } \\
\text { lattice structures } \\
\text { - It can model irregular strut } \\
\text { thickness by varying the } \\
\text { diameter and stiffness of the } \\
\text { beam element }\end{array}$ & $\begin{array}{l}\text { - The assumption of beam } \\
\text { element requires slender strut, } \\
\text { which is not applicable to stout } \\
\text { strut } \\
\text { - It cannot accurately model the } \\
\text { manufacturing defects. } \\
\text { - The joint of the strut cannot be } \\
\text { accurately modeled by beam } \\
\text { elements }\end{array}$ \\
\hline $\begin{array}{ll}\text { FE } & \text { Model with } \\
\text { 3D } & \text { Solid } \\
\text { Elements } & \end{array}$ & $\begin{array}{l}\text { - As-fabricated model by X- } \\
\text { ray image can accurately } \\
\text { reflect the manufacturing } \\
\text { influence } \\
\text { - It can model lattice } \\
\text { structures with solid skins } \\
\text { - It can reflect geometry of the } \\
\text { joint of the lattice structure }\end{array}$ & $\begin{array}{l}\text { - High computational cost for } \\
\text { large lattice structures } \\
\text { - Difficult to mesh the thin strut } \\
\text { - Mesh quality might be poor }\end{array}$ \\
\hline
\end{tabular}




\subsubsection{Beam element model}

In the early stage, beam elements are prevalently used in FE modeling of lattice structures $[38,90-94]$. To determine the effective elastic properties of random lattice structures, the homogenization modeling approach is inappropriate because it does not account for the natural variation in microstructure for random lattices. To overcome this difficulty, Zhu et al. $[90,91]$ used FEA to determine the equivalent Young's modulus, shear modulus and bulk modulus of 2D Voronoi honeycombs and 3D open-cell foams. Each strut was meshed with one to five Timoshenko beam elements according to the length of the strut. The effect of structural irregularity on the elastic properties was investigated. It is found that higher irregularity will increase the Young's modulus and shear modulus, but decrease the bulk modulus of the structure. The effects of the topological and microstructural irregularity of lattices are further investigate by the FE model to understand the stretch and bending mechanical response $[95,96]$. Then, a similar FE model was proposed to investigate the relationship between the elastic properties and the relative density of 3D Voronoi models [93]. It was found that the Kelvin foams can represent Voronoi foams in the low density regime. And the elastic modulus is sensitive to the imperfections while the compressive plateau stress is less sensitive. Furthermore, the elastic buckling of cell edges at the microscopic level is the dominant mechanism for compressive failures. Zhou et al. [92] found that the tensile strengths of individual struts of a lattice structure exhibit significant scatter which is attributed to the presence of defects or voids. They used Timoshenko beam elements to construct the finite element model with various mechanical property input data to reflect the measured strength of individual struts. The result showed that the variations in the input data strongly influence the predicted stress-strain behavior. 


\subsubsection{Solid element model}

Even though the FE model constructed by the beam element has a lower computational cost, not all types of the lattice structures can be meshed with beam elements. For instance, if the strut of the lattice structure is stout, it does not satisfy the assumptions of the beam element in FEA. It has been shown that with the decrease of porosity, which means the lattice struts get thicker, the mechanical property obtained from beam element model deviates from the experimental result [97]. Besides, in some cases, the lattice structure is connected with skin [98] or solid parts to serve certain functions [47]. Therefore, 3D solid elements are alternative choices in the FE modeling process to mesh the lattice structure. Chantarapanich et al. [99] used ten-node tetrahedron elements to investigate the mechanical response and the connectivity of different types of lattice topologies. Because the lattice cells were not connected by sharing nodes, it cannot be simulated by beam elements. Another advantage of 3D element FE model is that it can analyse the influence of the notch effect and the material concentration in the connection area of lattice struts which can predict a more accurate stress distribution in these locations [23]. It has been shown by the solid element FE model that, with the same porosity, the effective Young's modulus of the lattice structure will change dramatically by shifting the material from the edge to the vertices [100]. Besides, for the large deformation and nonlinear explicit dynamic analysis, the linear 3D elements with lumped mass matrix are required. Tetrahedral, triangular prism and brick elements were used together by Ullah et al. [101] to minimize the stress jump at the transition point in the explicit dynamic analysis of Kagome lattice core structures. Salonitis et al. [102] implemented a hybrid FE model to simulate the mechanical performance of the lattice structure combined with the solid material. Firstly, the effective Young's modulus and Poisson's ratio of the lattice structure 
are calculated by a beam element FE model. Then the lattice cells are modeled as representative volume elements (RVEs) with the estimated mechanical properties and the solid material is modeled with tetrahedral elements. The computational cost is reduced by using the RVEs for lattice structures. A similar approach was taken by Huo et al. [103] as shown in Figure 6. The mechanical properties of the lattice structure were obtained by a local FE model with tetrahedral elements in the first step. Then the lattice structure was substituted by a solid material with the homogenised mechanical properties. Finally, the homogenised lattice was connected to other solid materials and the global FE model is constructed. This approach is similar to the homogenization method. The difference is that the homogenised property is calculated by FE methods and the lattice struct is meshed with solid elements. The computational cost of the RVE model is higher than the homogenization method due to the fine mesh on the RVE. But this method is easy to implement because the homogenization is relatively complicated from a mathematical perspective.

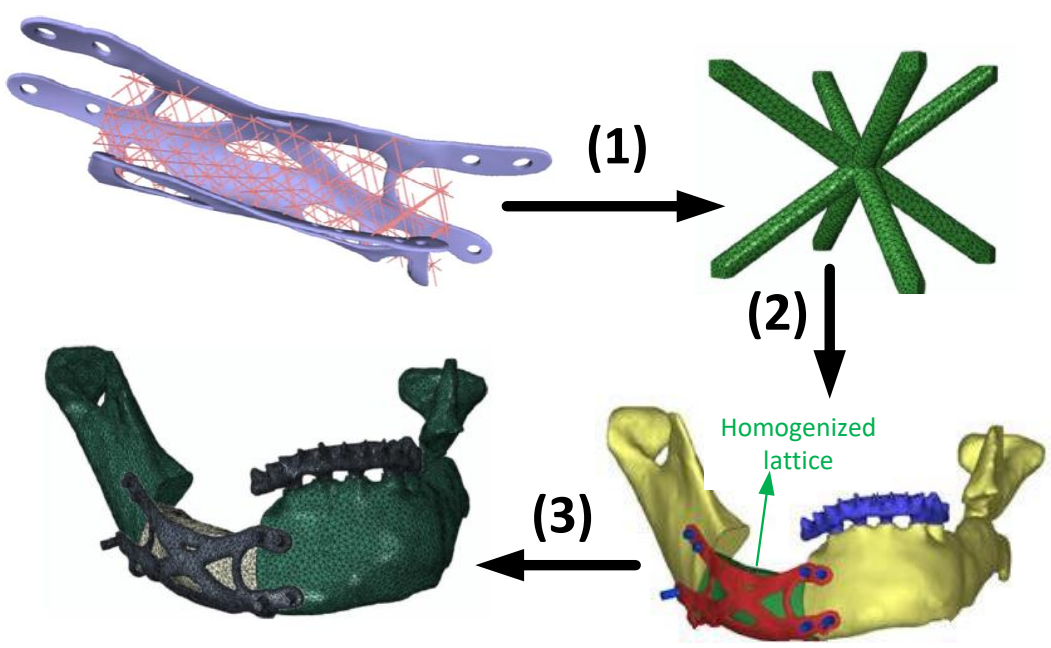

Figure 6. Hybrid FE model to analysis the lattice structure connected to solid materials 
In the field of orthopaedic tissue engineering, AM techniques allow for the production of lattice structures for tissue replacement. FE modeling is needed for virtual design and characterization to improve both the biological functionality and mechanical longevity of the lattice structure. Wettergreen et al. [104] proposed characterization and documentation of a library of micro-architectures and meshed the building blocks by polyhedral element in FE modeling process. The effect of the unit block porosity on the equivalent mechanical properties has been investigated through FE models. Malek et al. [47] implemented the FE model with tetrahedral elements to investigate the mechanical properties of cubical lattice structures made by medical grade $\mathrm{CoCr}$ alloy with porosity ranging from $60 \%$ to $80 \%$ fabricated by SLM process. They compared the estimated elastic modulus to the experiment result which showed good agreement.

\subsubsection{Improvement of FE models}

However, in some investigations, discrepancies are found comparing the numerical simulation to the experimental result [105-107]. This is due to the difference between manufactured and designed lattice structures in shapes, sizes, micro-porosities [108] and complex strut joint geometry [46]. Therefore, existing FE models still need further refinements to obtain more accurate results.

A common feature of the AM fabricated lattice structures is the material concentration in the nodal region [51]. There are two ways to consider this feature in the beam element model. One is that the beam element in the vicinity of the joint can be increased to the real thickness of the lattice strut $[45,51]$. Another way is to increase the stiffness of the beam element near the nodal region to compensate for the material aggregation [38]. Because the 
thickness of the strut near the nodal region can be directly measured, the first method is easier to be implemented.

The presence of microvoid in lattice struts and the nonuniform strut thickness caused by surface roughness will also lead to inaccurate simulation result. The FE model of two scaffolds with the same porosity are shown in Figure 7. It is found that the effective modulus of the scaffold with smooth surfaces is $68 \%$ higher than the model with rough surfaces. Using the measured dimension of fabricated samples to update the CAD model dimensions can improve the simulation accuracy for FEA [109]. Another way to consider the variation of the strut thickness is to use beam elements $[41,44,110]$ with different diameters to discretize the lattice strut as shown in Figure 8. Campoli et al. [44] used Scanning Electron Microscopy (SEM) and Gaussian distribution to determine the diameter of each beam. Then the FE model was simulated several times to get the mean and standard deviation of the mechanical properties which means the lattice structure may have a range of mechanical properties due to the structural irregularity. 


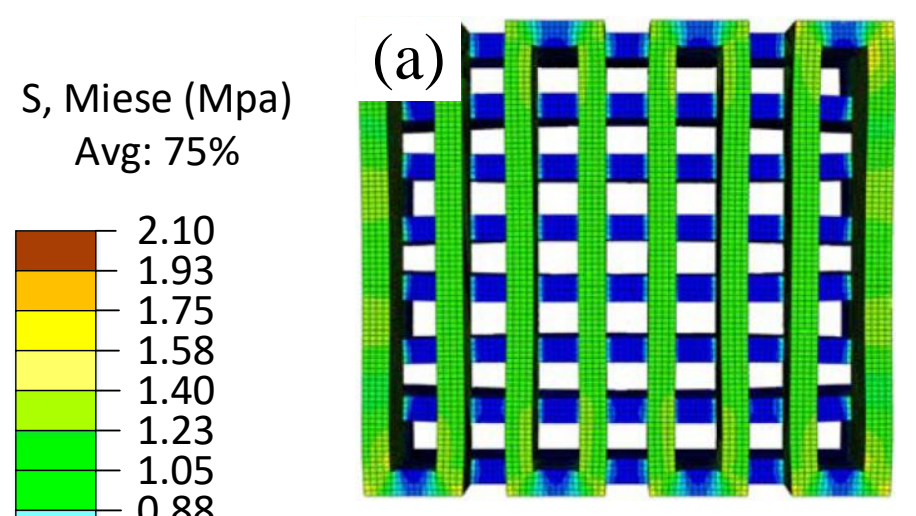

0.88
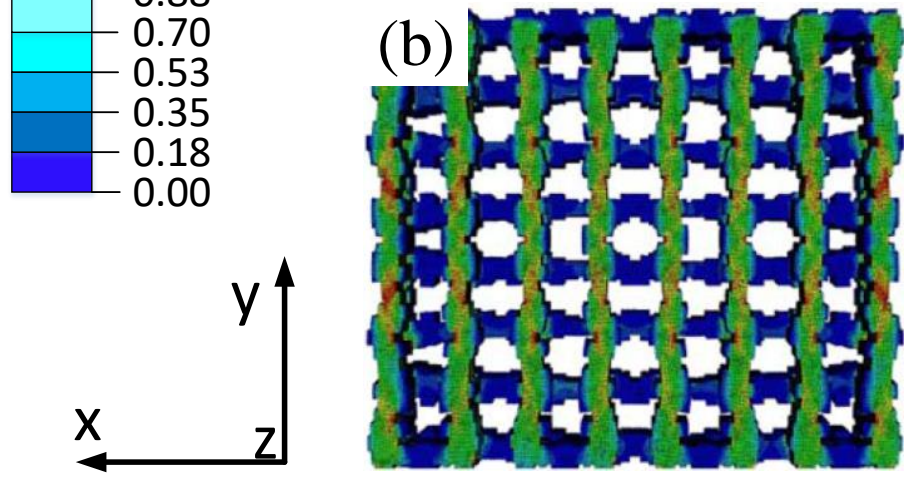

Figure 7. Contour plot of von Mises stress distribution (MPa) for two scaffolds with exactly the same porosity that were compressed in the y direction, (a) smooth surface, (b) irregular surface
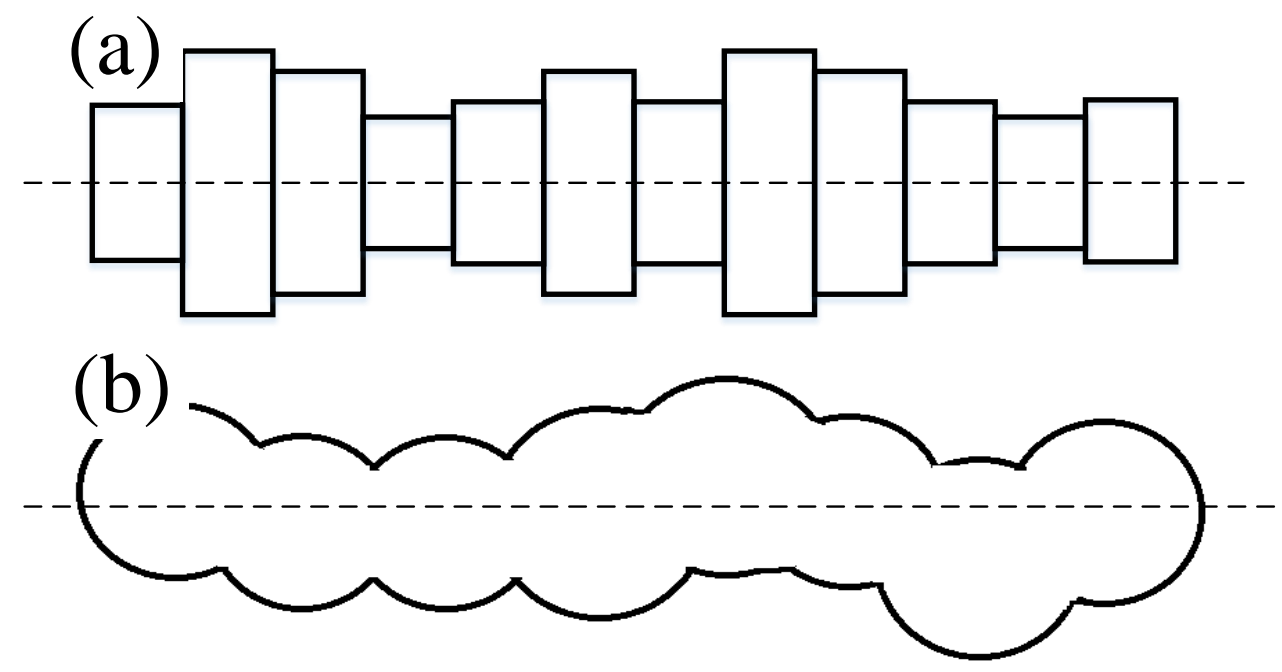

Figure 8. Beam elements with varied diameters to model the irregular strut, (a) implementation in FE model, (b) actual irregularity 
Image-based FEA has also been used to simulate the mechanical properties of lattice structures. This approach is the most accurate way to capture the as-fabricated geometry, because the FE model is directly built on the Micro-CT images through which the manufacturing defection can be precisely reflected. Williams et al. [39] experimentally and computationally tested the lattice structure made by Polycaprolactone (PCL) which is a bioresorbable polymer. It is concluded that the image-based FE model can estimate the mechanical properties of tissue lattice structure, bypassing the need for experimental testing. Suard et al. [58] used X-ray tomography to get the image of single strut of the lattice structure and computed the effective stiffness of strut with different build orientations by FEA. A concept called "effective volume ratio" was defined to set the lower bound of the stiffness. Then, the lattice structure was modeled by struts with effective volume ratio instead of the desired geometry. The result showed 5\% difference of Young's modulus between different build orientations. Except for the stiffness, it was found from the X-Ray tomography and corresponding FE model that the failure mechanism is also influenced by the poor build quality of AM process [111].

\section{AM Fabrication modeling}

\subsection{Manufacturing Discrepancy}

To design and simulate the lattice structure, the manufacturing influence of AM cannot be neglected. In the early stage, the design and simulation of lattice structures mainly focus on the geometrical parameters. The design model is directly imported into the simulation process. However, manufacturing discrepancy is a critical issue in the fabrication process of AM techniques [50]. Recently, extensive literatures have investigated the influence of the manufacturing discrepancy on the mechanical properties of lattice structures by 
experiments. And researchers have incorporated the manufacturing influence of AM in the simulation process as summarized in Table 3. Therefore, the understanding of the manufacturing discrepancy is crucial in the design and simulation process of lattice structures.

Table 3 Manufacturing influence considered in the simulation process

\begin{tabular}{|c|c|c|}
\hline & & Manufacturing influence \\
\hline \multirow[t]{2}{*}{$\begin{array}{l}\text { Homogenization } \\
\text { method }\end{array}$} & Park et al. [85] & $\begin{array}{l}\text { Layer deposition parameter and as- } \\
\text { fabricated cross sections }\end{array}$ \\
\hline & Park and Rosen [76] & Semi-rigid joint and layer deposition pattern \\
\hline \multirow{4}{*}{$\begin{array}{l}\text { FE model with } \\
\text { beam elements }\end{array}$} & Zhou et al. [92] & $\begin{array}{l}\text { Various mechanical properties of individual } \\
\text { lattice struts }\end{array}$ \\
\hline & $\begin{array}{l}\text { Labeas and Sunaric } \\
\text { [51] } \\
\text { Smith et al. [45] }\end{array}$ & $\begin{array}{l}\text { Increase thickness of beam elements in the } \\
\text { vicinity of the joint for material aggregation }\end{array}$ \\
\hline & Luxner et al. [38] & $\begin{array}{l}\text { Increase stiffness of beam elements in the } \\
\text { vicinity of the joint for material aggregation }\end{array}$ \\
\hline & $\begin{array}{l}\text { Campoli et al. [44] } \\
\text { Zargarian et al. [110] } \\
\text { Ravari et al. [41] }\end{array}$ & Irregular surface modeled by beam elements \\
\hline \multirow{6}{*}{$\begin{array}{l}\text { FE model with } \\
\text { 3D solid } \\
\text { elements }\end{array}$} & Yang et al. [109] & $\begin{array}{l}\text { Average value of measure dimension to } \\
\text { update the dimension of the } C A D \text { model }\end{array}$ \\
\hline & Cansizoglu et al. [42] & The influence of strut angles on the thickness \\
\hline & $\begin{array}{l}\text { Williams et al. [39] } \\
\text { Sercombe et al. [111] }\end{array}$ & $\begin{array}{l}\text { Image-based FE model to incorporate } \\
\text { manufacturing defects }\end{array}$ \\
\hline & Suard el al. [58] & $\begin{array}{l}\text { X-ray tomography is used to get the effective } \\
\text { volume ratio of lattice struts }\end{array}$ \\
\hline & $\begin{array}{l}\text { Cahill et al. [105] } \\
\text { Ravari et al. [41] }\end{array}$ & $\begin{array}{l}\text { Irregular surface of lattice strut modeled by } \\
\text { 3D solid elements }\end{array}$ \\
\hline & Park and Rosen [112] & $\begin{array}{l}\text { Stair-step irregularities between layers and } \\
\text { the air gaps generated among the filaments }\end{array}$ \\
\hline
\end{tabular}

The irregularity of the surface finishing is one of the most common discrepancies of the AM fabricated components. Because of the layer by layer principle, the AM fabricated model generally has the stair-step irregularities corresponding to the slicing process. Recently, a voxel-based as-fabricated modeling technique is implemented to consider the 
stair-step irregularities between layers and the air gaps generated among the filaments in the AM process [112]. Besides, the accuracy of the printing head is limited and the manufacturing process is unstable, which will also cause discrepancies and defects on the surface of the as-fabricated part. For the lattice structure, the manufacturing discrepancy problem becomes even more significant. Because the dimension of the lattice strut is relatively small and the stair-step irregularities will appear on the inclined strut. Cansizoglu et al. [42] found that the fabricated strut thickness grows larger if the angle between the strut and the horizontal plane increases. And there could be a significant change in modulus for variations as small as $0.1 \mathrm{~mm}$ in the strut thickness. Consequently, the FEA predicted stiffness based on the CAD model could be slightly lower than the actual stiffness. It is also found that the strut lying normal to the build direction is more likely to have defects on the surface [60].

Another reason causing the surface irregularity is the presence of unmelted power attached to the surface of AM fabricated component [22]. It has been found that process parameters of laser based AM techniques have strong influence on the surface roughness [113, 114]. By optimizing the process parameters, the surface roughness of AM fabricated components can be reduced. Nevertheless, the influence of the surface roughness on the mechanical properties still cannot be neglected. Everhart et al. [115] investigated the effect of surface roughness on the tensile behavior of bars fabricated by AM. The result showed that the unfinished tensile bar, which has a rougher surface, exhibited lower yield strength than the machined one. And the elongation of the unfinished sample is much lower than that of the machined sample. It is also mentioned that additional data for the surface characterization process need to be implemented in the FE model to reduce the error in the plastic region. 
Because the AM fabricated lattice structure consists of unfinished single struts, it is difficult to accurately predict the mechanical property if the effect of the unfinished surface is neglected.

Post-processing is able to reduce the surface roughness and the defects of the lattice structure fabricated by AM. Formanoir et al. [43] use chemical etching to decrease the roughness of octet-truss lattice structures manufactured by EBM. This approach can improve the mechanical efficiency of the structure by removing the unmelted powders on the surface. It was also found that the elongation was increased because the critical surface defects are removed during the etching process which was more resistant to the crack initiation. However, this process reduced the strut thickness by almost 30\%. The diameter of the strut in the simulation model should be modified.

\subsection{Anisotropic Mechanical Behavior}

Apart from the manufacturing discrepancy, the anisotropic material property of AM fabricated parts is another important aspect that needs to be considered in design and simulation of lattice structures. It is found in the literature that the mechanical properties are different in directions parallel and perpendicular to the building direction among most AM processes.

The layer by layer manufacturing principle is one of the reasons causing the anisotropic material properties. Shanjani et al. [116] investigated the effect of the printing orientation on the mechanical characteristics of porous calcium polyphosphate structures fabricated by BJ process. It was found that samples with layers deposited parallel to the compressive loading direction were $48 \%$ stronger than those with layers deposited perpendicular to the load. Ladani et al. [117] studied the anisotropic mechanical behavior of EBM process. The 
result showed that the in-plane properties such as elastic modulus, yield strength, ultimate tensile strength were much higher than out-of-plane direction due to defects or imperfect bonding between layers. Sridharan et al. [118] analyzed the reason for anisotropic mechanical properties of Al-6061 fabricated via Ultrasonic Additive Manufacturing (UAM). When the load was perpendicular to the interfaces, a brittle failure was observed due to the onset of strain localization during the UAM process instead of the lack of bonding between each layer. For the FDM process, the printing orientation also has significant influence on the mechanical properties such as the tensile, compressive strength [119] and deformation behavior [120]. To predict such properties, an anisotropic FE model for FDM process has been proposed by measuring the material properties of test specimens printed in multiple orientations [121].

In some AM processes, the anisotropic mechanical performance is attributed to the anisotropic microstructure of the component. Anisotropic mechanical properties of Ti6Al4V component fabricated by Directed Energy Deposition (DED) have been studied [122]. The result showed that the elongation in longitudinal direction and transverse direction was $11 \%$ and $14 \%$ respectively due to the columnar prior $-\beta$ grain morphology and the grain boundary $\alpha$. Akerfeldt et al. [123] also found that the microstructural constituents have influence on the anisotropic elongation rate of the Ti6Al4V specimen fabricated by laser metal wire-deposition process. Zhang et al. [124] investigated the correlation between the microstructure and the anisotropic tensile behavior of TC21 alloy fabricated by the DED process. The result shows that the sample vertical to the building platform exhibit better ductility due to the lack of continuous grain boundary $\alpha$ layers. But 
horizontal samples show inferior ductility because of the columnar $\beta$ grain morphology and continuous grain boundary $\alpha$ layers.

For AM fabricated lattice structures, the anisotropic material property also has significant influence on the mechanical properties. It was found that the ultimate tensile and yield strength of SLM fabricated 316L stainless steel lattice structures were approximately $60 \%$ higher and the elongation were $40 \%$ higher in vertical building direction than in horizontal building direction [53]. Similar result was presented by Wauthle et al. [125] that the horizontal strut was weak which should be avoided in SLM process. Reinhart et al. [126] investigated the relationship between the mechanical properties and the geometrical properties of the single lattice strut manufactured by SLM process. The result showed that for different diameters and different polar angles of the strut, the Young's modulus was different, which is shown in Figure 9. Therefore, it is not accurate to simulate the mechanical properties of the lattice structure with isotropic material properties. For EBM fabricated lattice structures, anisotropic mechanical properties were also observed by exerting loads parallel and perpendicular to the build direction [127]. For the BJ process, Galeta et al. [128] investigated the effect of building orientation on the mechanical properties of 2D lattice structures. The result showed that the building axis $\mathrm{Y}$ provided better strength than those oriented along $\mathrm{X}$ axis. And the 2D sample parallel to the printing bed exhibited slightly better strength than those perpendicular to the printing bed. Castilho et al. [129] also studied the influence of the printing direction of the BJ process and found that the mechanical behavior was highly influenced by the printing direction though the dimensional variation is almost the same. Therefore, a correction factor is needed in the calculation of the mechanical properties to balance the effects of the building direction and 
the dimensional deviation. Recently, to simplify the anisotropic material properties, a transversely isotropic FE model was proposed to consider the influence of the printing direction on the mechanical behavior of lattice structures [130]. The result of the simulation was in good agreement with that of the experiment, which suggested that the model can estimate the deformation of the lattice structures quite well. However, it was also found that the failure initiation predicted by the simulation model is less accurate than the mechanical behavior before failure, which indicated that further investigation was still needed.

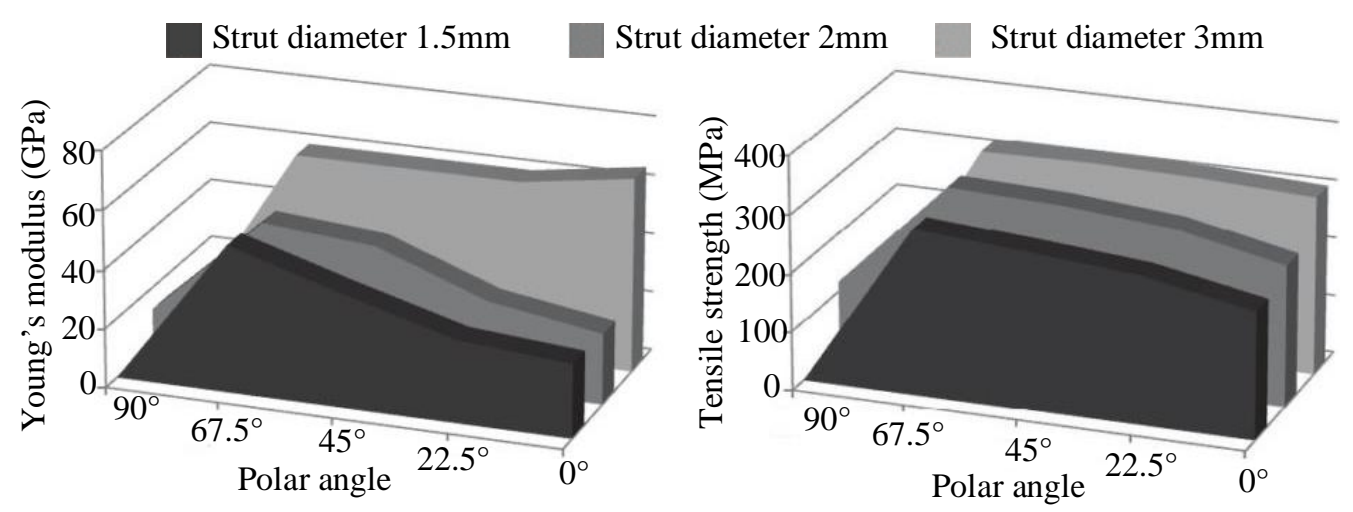

Figure 9. Young's modulus and tensile strength as a function of polar angle and strut diameter

\section{Conclusion and Perspectives}

Additive Manufacturing has provided designers with not only great opportunities but also enormous challenges in designing and modeling of lattice structures. To evaluate the mechanical properties of lattice structures, experimental methods, homogenization methods and FE models have been proposed and widely used by designers. Due to the high manufacturing cost and time, it is unpractical to obtain the mechanical properties of lattice structures only by conducting experiments in engineering applications. Simulation modeling such as the homogenization and FE methods play significant roles in estimating 
the mechanical performance of lattice structures. However, each modeling approach has its advantages and disadvantages. Based on the characteristics of lattice structures, appropriate modeling approach should be implemented to improve the accuracy while minimizing the computational cost.

During simulation of lattice structures, the manufacturing influence of AM processes cannot be neglected by designers. It has been shown by a lot of literatures that the geometrical discrepancy is a critical issue which may cause inferior mechanical properties. The effect of irregular surfaces and shapes on the mechanical properties of lattice structures should be considered in the design and simulation process. It is also acknowledged that the material properties of AM fabricated components exhibit anisotropy, which should also be considered in the simulation process. At last, based on the review, several future works concerning the modeling of lattice structure for the simulation have been pointed out:

New simulation method for Lattice-Solid hybrid structure should be developed. To serve certain functions, lattice structures are usually connected with solid materials. Though homogenized lattice structure can be represented by an equivalent material. It is not applicable for heterogeneous lattices. Besides, using solid element to model the hybrid structure will result in high computational cost due to the small size of the mesh on the lattice structure. A new approach that can efficiently model Lattice-Solid hybrid structure should be proposed.

Anisotropic material properties should be implemented in the modeling of the lattice structure. It has been presented by many literatures that the material properties of AM fabricated components are anisotropic, the lattice structure is no exception. And it is also found by experimental methods that the mechanical properties of lattice 
structures have correlation with the printing orientation. Therefore, anisotropic material properties should be considered in the simulation of lattice structures.

Multi-physics design and simulation model is needed for lattice structures including the heat transfer, fluid mechanics and solid mechanics. The lattice structure is promising in serving as multi-functional materials in engineering applications. A multi-physics model that can design and simulate the mechanical properties, thermal properties and fluid dynamics of lattice structures simultaneously will prompt the application of the lattice structure into a higher level.

\section{Reference}

[1] Merriam-Webster, 2016, "lattice," http://www.merriamwebster.com/dictionary/lattice.

[2] Schaedler, T. A., and Carter, W. B., 2016, "Architected Cellular Materials," Annual Review of Materials Research, pp. 187-210. doi: 10.1146/annurev-matsci-070115031624

[3] Evans, A. G., Hutchinson, J., and Ashby, M., 1998, "Multifunctionality of cellular metal systems," Progress in Materials Science, 43(3), pp. 171-221. doi: 10.1016/S0079-6425(98)00004-8

[4] Gibson, L. J., and Ashby, M. F., 2014, Cellular solids: Structure and properties, second edition. doi: 10.1017/CBO9781139878326

[5] Tang, Y., and Zhao, Y. F., 2016, "A survey of the design methods for additive manufacturing to improve functional performance," Rapid Prototyping Journal, 22(3), pp. 569-590. doi: 10.1108/RPJ-01-2015-0011

[6] Wang, H., Chen, Y., and Rosen, D. W., "A hybrid geometric modeling method for large scale conformal cellular structures," Proc. ASME Computers and Information in Engineering Conference, Long Beach, California. doi: 10.1115/DETC200585366

[7] Wang, H., and Rosen, D. W., 2002, "Parametric Modeling Method for Truss Structures," (36215), pp. 759-767. doi: 10.1115/DETC2002/CIE-34495

[8] Wang, H. V., 2005, "A unit cell approach for lightweight structure and compliant mechanism," Citeseer. uri: http://hdl.handle.net/1853/7561

[9] Nguyen, J., Park, S., Rosen, D. W., Folgar, L., and Williams, J., "Conformal lattice structure design and fabrication," Proc. Solid Freeform Fabrication Symposium, Austin, TX.

[10] Queheillalt, D. T., and Wadley, H. N., 2005, "Cellular metal lattices with hollow trusses," Acta Materialia, 53(2), pp. 303-313. doi: 10.1016/j.actamat.2004.09.024 
[11] Clough, E. C., Ensberg, J., Eckel, Z. C., Ro, C. J., and Schaedler, T. A., 2016, "Mechanical performance of hollow tetrahedral truss cores," International Journal of Solids and Structures, 91, pp. 115-126. doi: 10.1016/j.ijsolstr.2016.04.006

[12] Schaedler, T. A., Ro, C. J., Sorensen, A. E., Eckel, Z., Yang, S. S., Carter, W. B., and Jacobsen, A. J., 2014, "Designing metallic microlattices for energy absorber applications," Advanced Engineering Materials, 16(3), pp. 276-283. doi: 10.1002/adem.201300206

[13] Lu, T. J., Valdevit, L., and Evans, A. G., 2005, "Active cooling by metallic sandwich structures with periodic cores," Progress in Materials Science, 50(7), pp. 789-815. doi: 10.1016/j.pmatsci.2005.03.001

[14] Wadley, H. N., and Queheillalt, D. T., "Thermal applications of cellular lattice structures," Proc. Materials science forum, Trans Tech Publ, pp. 242-247. doi: 10.4028/www.scientific.net/MSF.539-543.242

[15] Valdevit, L., Pantano, A., Stone, H. A., and Evans, A. G., 2006, "Optimal active cooling performance of metallic sandwich panels with prismatic cores," International Journal of Heat and Mass Transfer, 49(21), pp. 3819-3830. doi: 10.1016/j.ijheatmasstransfer.2006.03.042

[16] Mota, C., Puppi, D., Chiellini, F., and Chiellini, E., 2015, "Additive manufacturing techniques for the production of tissue engineering constructs," Journal of tissue engineering and regenerative medicine, 9(3), pp. 174-190. doi: 10.1002/term.1635

[17] ASTM-F2792-12a, 2012, "Standard Terminology for Additive Manufacturing Technologies." doi: 10.1520/F2792-12A

[18] Melchels, F. P. W., Feijen, J., and Grijpma, D. W., 2010, "A review on stereolithography and its applications in biomedical engineering," Biomaterials, 31(24), pp. 6121-6130. doi: 10.1016/j.biomaterials.2010.04.050

[19] Rezaei, R., Ravari, M. K., Badrossamay, M., and Kadkhodaei, M., 2016, "Mechanical characterization and finite element modeling of polylactic acid BCC$\mathrm{Z}$ cellular lattice structures fabricated by fused deposition modeling," Proceedings of the Institution of Mechanical Engineers, Part C: Journal of Mechanical Engineering Science, Vol 231, Issue 11, pp. 1995 - 2004. doi: 10.1177/0954406215626941

[20] Naghieh, S., Karamooz Ravari, M. R., Badrossamay, M., Foroozmehr, E., and Kadkhodaei, M., 2016, "Numerical investigation of the mechanical properties of the additive manufactured bone scaffolds fabricated by FDM: The effect of layer penetration and post-heating," Journal of the Mechanical Behavior of Biomedical Materials, 59, pp. 241-250. doi: 10.1016/j.jmbbm.2016.01.031

[21] Tang, Y., Zhou, Y., Hoff, T., Garon, M., and Zhao, Y. F., 2016, "Elastic modulus of 316 stainless steel lattice structure fabricated via binder jetting process," Materials Science and Technology (United Kingdom), 32(7), pp. 648-656. doi: 10.1179/1743284715Y.0000000084

[22] Yan, C., Hao, L., Hussein, A., and Raymont, D., 2012, "Evaluations of cellular lattice structures manufactured using selective laser melting," International Journal of Machine Tools and Manufacture, 62, pp. 32-38. doi: 10.1016/j.ijmachtools.2012.06.002

[23] Cerardi, A., Caneri, M., Meneghello, R., Concheri, G., and Ricotta, M., 2013, "Mechanical characterization of polyamide cellular structures fabricated using 
selective laser sintering technologies," Materials and Design, 46, pp. 910-915. doi: 10.1016/j.matdes.2012.11.042

[24] Murr, L. E., Gaytan, S. M., Medina, F., Lopez, M. I., Martinez, E., and Wicker, R. B., "Additive layered manufacturing of reticulated Ti-6Al-4V biomedical mesh structures by electron beam melting," Proc. 25th Southern Biomedical Engineering Conference 2009, pp. 23-28. doi: 10.1007/978-3-642-01697-4_11

[25] Parthasarathy, J., Starly, B., Raman, S., and Christensen, A., 2010, "Mechanical evaluation of porous titanium (Ti6Al4V) structures with electron beam melting (EBM)," Journal of the Mechanical Behavior of Biomedical Materials, 3(3), pp. 249259. doi: 10.1016/j.jmbbm.2009.10.006

[26] Mun, J., Yun, B. G., Ju, J., and Chang, B. M., 2015, "Indirect additive manufacturing based casting of a periodic 3D cellular metal - Flow simulation of molten aluminum alloy," Journal of Manufacturing Processes, 17, pp. 28-40. doi: 10.1016/j.jmapro.2014.11.001

[27] Schaedler, T. A., Jacobsen, A. J., Torrents, A., Sorensen, A. E., Lian, J., Greer, J. R., Valdevit, L., and Carter, W. B., 2011, "Ultralight metallic microlattices," Science, 334(6058), pp. 962-965. doi: 10.1126/science.1211649

[28] Cheung, K. C., and Gershenfeld, N., 2013, "Reversibly assembled cellular composite materials," Science, 341(6151), pp. 1219-1221. doi: 10.1126/science. 1240889

[29] Rosen, D. W., 2007, "Computer-Aided Design for Additive Manufacturing of Cellular Structures," Computer-Aided Design and Applications, 4(5), pp. 585-594. doi: 10.1080/16864360.2007.10738493

[30] Yang, L., Harrysson, O., Cormier, D., West, H., Gong, H., and Stucker, B., 2015, "Additive Manufacturing of Metal Cellular Structures: Design and Fabrication," JOM, 67(3), pp. 608-615. doi: 10.1007/s11837-015-1322-y

[31] Seepersad, C. C., Shahan, D., and Madhavan, K., "Multiscale design for solid freeform fabrication," Proc. Solid Freeform Fabrication Symposium.

[32] Tang, Y., Dong, G., Zhou, Q., and Zhao, Y. F., 2017, "Lattice Structure Design and Optimization With Additive Manufacturing Constraints," IEEE Transactions on Automation Science and Engineering, PP(99), pp. 1-17. doi: 10.1109/TASE.2017.2685643

[33] Gibson, L., Ashby, M., Schajer, G., and Robertson, C., "The mechanics of twodimensional cellular materials," Proc. Proceedings of the Royal Society of London A: Mathematical, Physical and Engineering Sciences, The Royal Society, pp. 25-42. doi: 10.1098/rspa.1982.0087

[34] Gibson, L. J., and Ashby, M. F., "The mechanics of three-dimensional cellular materials," Proc. Proceedings of the Royal Society of London A: Mathematical, Physical and Engineering Sciences, The Royal Society, pp. 43-59. doi: 10.1098/rspa.1982.0088

[35] Ashby, M. F., and Medalist, R. F. M., 1983, "The mechanical properties of cellular solids," Metallurgical Transactions A, 14(9), pp. 1755-1769. doi: 10.1007/bf02645546

[36] Gibson, L. J., and Ashby, M. F., 1997, Cellular solids: Structure and properties, second edition. doi: 10.1017/CBO9781139878326 
[37] Gibson, L. J., 2005, "Biomechanics of cellular solids," Journal of Biomechanics, 38(3), pp. 377-399. doi: 10.1016/j.jbiomech.2004.09.027

[38] Luxner, M. H., Stampfl, J., and Pettermann, H. E., 2005, "Finite element modeling concepts and linear analyses of 3D regular open cell structures," Journal of Materials Science, 40(22), pp. 5859-5866. doi: 10.1007/s10853-005-5020-y

[39] Williams, J. M., Adewunmi, A., Schek, R. M., Flanagan, C. L., Krebsbach, P. H., Feinberg, S. E., Hollister, S. J., and Das, S., 2005, "Bone tissue engineering using polycaprolactone scaffolds fabricated via selective laser sintering," Biomaterials, 26(23), pp. 4817-4827. doi: http://dx.doi.org/10.1016/j.biomaterials.2004.11.057

[40] Johnston, S. R., Reed, M., Wang, H. V., and Rosen, D. W., "Analysis of mesostructure unit cells comprised of octet-truss structures," Proc. 17th Solid Freeform Fabrication Symposium, SFF 2006, pp. 421-432.

[41] Karamooz Ravari, M. R., Kadkhodaei, M., Badrossamay, M., and Rezaei, R., 2014, "Numerical investigation on mechanical properties of cellular lattice structures fabricated by fused deposition modeling," International Journal of Mechanical Sciences, 88, pp. 154-161. doi: 10.1016/j.ijmecsci.2014.08.009

[42] Cansizoglu, O., Harrysson, O., Cormier, D., West, H., and Mahale, T., 2008, "Properties of Ti-6Al-4V non-stochastic lattice structures fabricated via electron beam melting," Materials Science and Engineering: A, 492(1-2), pp. 468-474. doi: http://dx.doi.org/10.1016/j.msea.2008.04.002

[43] de Formanoir, C. C. C., 2016, "Improving the mechanical efficiency of electron beam melted titanium lattice structures by chemical etching," Additive Manufacturing, 11, pp. 71-76. doi: 10.1016/j.addma.2016.05.001

[44] Campoli, G., Borleffs, M. S., Amin Yavari, S., Wauthle, R., Weinans, H., and Zadpoor, A. A., 2013, "Mechanical properties of open-cell metallic biomaterials manufactured using additive manufacturing," Materials \& Design, 49, pp. 957-965. doi: http://dx.doi.org/10.1016/j.matdes.2013.01.071

[45] Smith, M., Guan, Z., and Cantwell, W. J., 2013, "Finite element modelling of the compressive response of lattice structures manufactured using the selective laser melting technique," International Journal of Mechanical Sciences, 67, pp. 28-41. doi: http://dx.doi.org/10.1016/j.ijmecsci.2012.12.004

[46] Gümrük, R., and Mines, R. A. W., 2013, "Compressive behaviour of stainless steel micro-lattice structures," International Journal of Mechanical Sciences, 68, pp. 125139. doi: http://dx.doi.org/10.1016/j.ijmecsci.2013.01.006

[47] Abd Malek, N. M. S., Mohamed, S. R., Che Ghani, S. A., and Wan Harun, W. S., "Critical evaluation on structural stiffness of porous cellular structure of cobalt chromium alloy," Proc. IOP Conference Series: Materials Science and Engineering. doi: 10.1088/1757-899X/100/1/012019

[48] Yan, C., Hao, L., Hussein, A., Bubb, S. L., Young, P., and Raymont, D., 2014, "Evaluation of light-weight AlSi10Mg periodic cellular lattice structures fabricated via direct metal laser sintering," Journal of Materials Processing Technology, 214(4), pp. 856-864. doi: 10.1016/j.jmatprotec.2013.12.004

[49] Yan, C., Hao, L., Hussein, A., and Young, P., 2015, "Ti-6Al-4V triply periodic minimal surface structures for bone implants fabricated via selective laser melting," Journal of the Mechanical Behavior of Biomedical Materials, 51, pp. 61-73. doi: http://dx.doi.org/10.1016/j.jmbbm.2015.06.024 
[50] Arabnejad, S., Burnett Johnston, R., Pura, J. A., Singh, B., Tanzer, M., and Pasini, D., 2016, "High-strength porous biomaterials for bone replacement: A strategy to assess the interplay between cell morphology, mechanical properties, bone ingrowth and manufacturing constraints," Acta Biomaterialia, 30, pp. 345-356. doi: 10.1016/j.actbio.2015.10.048

[51] Labeas, G. N., and Sunaric, M. M., 2010, "Investigation on the Static Response and Failure Process of Metallic Open Lattice Cellular Structures," Strain, 46(2), pp. 195204. doi: 10.1111/j.1475-1305.2008.00498.x

[52] Yang, L., Cormier, D., West, H., Harrysson, O., and Knowlson, K., 2012, "Nonstochastic Ti-6Al-4V foam structures with negative Poisson's ratio," Materials Science and Engineering A, 558, pp. 579-585. doi: 10.1016/j.msea.2012.08.053

[53] Alsalla, H., Hao, L., and Smith, C., 2016, "Fracture toughness and tensile strength of $316 \mathrm{~L}$ stainless steel cellular lattice structures manufactured using the selective laser melting technique," Materials Science and Engineering: A, 669, pp. 1-6. doi: http://dx.doi.org/10.1016/j.msea.2016.05.075

[54] Winter, R. E., Cotton, M., Harris, E. J., Maw, J. R., Chapman, D. J., Eakins, D. E., and McShane, G., 2014, "Plate-impact loading of cellular structures formed by selective laser melting," Modelling and Simulation in Materials Science and Engineering, 22(2). doi: 10.1088/0965-0393/22/2/025021

[55] Salehian, A., and Inman, D. J., 2008, "Dynamic analysis of a lattice structure by homogenization: Experimental validation," Journal of Sound and Vibration, 316(15), pp. 180-197. doi: http://dx.doi.org/10.1016/j.jsv.2008.02.031

[56] Jamshidinia, M., Wang, L., Tong, W., Ajlouni, R., and Kovacevic, R., 2015, "Fatigue properties of a dental implant produced by electron beam melting (EBM)," Journal of Materials Processing Technology, 226, pp. 255-263. doi: 10.1016/j.jmatprotec.2015.07.013

[57] Yan, C., Hao, L., Hussein, A., Young, P., Huang, J., and Zhu, W., 2015, "Microstructure and mechanical properties of aluminium alloy cellular lattice structures manufactured by direct metal laser sintering," Materials Science and Engineering A, 628, pp. 238-246. doi: 10.1016/j.msea.2015.01.063

[58] Suard, M., Lhuissier, P., Dendievel, R., Blandin, J. J., Vignat, F., and Villeneuve, F., 2014, "Towards stiffness prediction of cellular structures made by electron beam melting (EBM)," Powder Metallurgy, 57(3), pp. 190-195. doi: 10.1179/1743290114Y.0000000093

[59] Qiu, C., Yue, S., Adkins, N. J. E., Ward, M., Hassanin, H., Lee, P. D., Withers, P. J., and Attallah, M. M., 2015, "Influence of processing conditions on strut structure and compressive properties of cellular lattice structures fabricated by selective laser melting," Materials Science and Engineering A, 628, pp. 188-197. doi: 10.1016/j.msea.2015.01.031

[60] Hernández-Nava, E., Smith, C. J., Derguti, F., Tammas-Williams, S., Leonard, F., Withers, P. J., Todd, I., and Goodall, R., 2016, "The effect of defects on the mechanical response of $\mathrm{Ti}-6 \mathrm{Al}-4 \mathrm{~V}$ cubic lattice structures fabricated by electron beam melting," Acta Materialia, 108, pp. 279-292. doi: http://dx.doi.org/10.1016/j.actamat.2016.02.029

[61] Hassani, B., and Hinton, E., 1998, "A review of homogenization and topology optimization I-homogenization theory for media with periodic structure," 
Computers \& Structures, 69(6), pp. 707-717. doi: http://dx.doi.org/10.1016/S00457949(98)00131-X

[62] Bensoussan, A., Lions, J.-L., and Papanicolaou, G., 1978, Asymptotic analysis for periodic structures, American Mathematical Soc.

[63] Cioranescu, D., and Paulin, J. S. J., 1979, "Homogenization in open sets with holes," Journal of Mathematical Analysis and Applications, 71(2), pp. 590-607. doi: http://dx.doi.org/10.1016/0022-247X(79)90211-7

[64] Ptochos, E., and Labeas, G., 2012, "Shear modulus determination of cuboid metallic open-lattice cellular structures by analytical, numerical and homogenisation methods," Strain, 48(5), pp. 415-429. doi: 10.1111/j.1475-1305.2012.00837.x

[65] Ptochos, E., and Labeas, G., 2012, "Elastic modulus and Poisson's ratio determination of micro-lattice cellular structures by analytical, numerical and homogenisation methods," Journal of Sandwich Structures and Materials, 14(5), pp. 597-626. doi: 10.1177/1099636212444285

[66] Bendsøe, M. P., and Kikuchi, N., 1988, "Generating optimal topologies in structural design using a homogenization method," Computer Methods in Applied Mechanics and Engineering, 71(2), pp. 197-224. doi: http://dx.doi.org/10.1016/00457825(88)90086-2

[67] Rabczuk, T., Kim, J., Samaniego, E., and Belytschko, T., 2004, "Homogenization of sandwich structures," International Journal for Numerical Methods in Engineering, 61(7), pp. 1009-1027. doi: 10.1002/nme.1100

[68] Florence, C., and Sab, K., 2005, "Overall ultimate yield surface of periodic tetrakaidecahedral lattice with non-symmetric material distribution," Journal of Materials Science, 40(22), pp. 5883-5892. doi: 10.1007/s10853-005-5023-8

[69] Florence, C., and Sab, K., 2006, "A rigorous homogenization method for the determination of the overall ultimate strength of periodic discrete media and an application to general hexagonal lattices of beams," European Journal of Mechanics, A/Solids, 25(1), pp. 72-97. doi: 10.1016/j.euromechsol.2005.06.011

[70] Arabnejad, S., and Pasini, D., 2013, "Mechanical properties of lattice materials via asymptotic homogenization and comparison with alternative homogenization methods," International Journal of Mechanical Sciences, 77, pp. 249-262. doi: http://dx.doi.org/10.1016/j.jijmecsci.2013.10.003

[71] Tollenaere, H., and Caillerie, D., 1998, "Continuous modeling of lattice structures by homogenization," Advances in Engineering Software, 29(7), pp. 699-705. doi: 10.1016/S0965-9978(98)00034-9

[72] Caillerie, D., Mourad, A., and Raoult, A., 2006, "Discrete Homogenization in Graphene Sheet Modeling," Journal of Elasticity, 84(1), pp. 33-68. doi: 10.1007/s10659-006-9053-5

[73] Dos Reis, F., and Ganghoffer, J., 2010, "Discrete homogenization of architectured materials: Implementation of the method in a simulation tool for the systematic prediction of their effective elastic properties," Technische Mechanik, 30(1-3), pp. 85-109.

[74] Dos Reis, F., and Ganghoffer, J. F., 2012, "Equivalent mechanical properties of auxetic lattices from discrete homogenization," Computational Materials Science, 51(1), pp. 314-321. doi: 10.1016/j.commatsci.2011.07.014 
[75] Dell'Isola, F., Giorgio, I., Pawlikowski, M., and Rizzi, N. L., 2016, "Large deformations of planar extensible beams and pantographic lattices: Heuristic homogenization, experimental and numerical examples of equilibrium," Proceedings of the Royal Society A: Mathematical, Physical and Engineering Sciences, 472(2185). doi: 10.1098/rspa.2015.0790

[76] Sang-in Park, D. W. R., 2016, "Homogenization of Mechanical Properties for Additively Manufactured Periodic Lattice Structures Considering Joint Stiffening Effects," IDETC/CIECharlotte, North Carolina. doi: 10.1115/DETC2016-59730

[77] Assidi, M., Dos Reis, F., and Ganghoffer, J. F., 2011, "Equivalent mechanical properties of biological membranes from lattice homogenization," Journal of the Mechanical Behavior of Biomedical Materials, 4(8), pp. 1833-1845. doi: 10.1016/j.jmbbm.2011.05.040

[78] Goda, I., Assidi, M., Belouettar, S., and Ganghoffer, J. F., 2012, "A micropolar anisotropic constitutive model of cancellous bone from discrete homogenization," Journal of the Mechanical Behavior of Biomedical Materials, 16(1), pp. 87-108. doi: 10.1016/j.jmbbm.2012.07.012

[79] Goda, I., Assidi, M., and Ganghoffer, J. F., 2014, "A 3D elastic micropolar model of vertebral trabecular bone from lattice homogenization of the bone microstructure," Biomechanics and Modeling in Mechanobiology, 13(1), pp. 53-83. doi: 10.1007/s10237-013-0486-z

[80] Goda, I., Dos Reis, F., and Ganghoffer, J. F., 2016, "Limit analysis of lattices based on the asymptotic homogenization method and prediction of size effects in bone plastic collapse," Advanced Structured Materials, pp. 179-211. doi: 10.1007/978-3319-31721-2_9

[81] Hutchinson, R., and Fleck, N., 2006, "The structural performance of the periodic truss," Journal of the Mechanics and Physics of Solids, 54(4), pp. 756-782. doi: 10.1016/j.jmps.2005.10.008

[82] Vigliotti, A., and Pasini, D., 2012, "Linear multiscale analysis and finite element validation of stretching and bending dominated lattice materials," Mechanics of Materials, 46, pp. 57-68. doi: 10.1016/j.mechmat.2011.11.009

[83] Vigliotti, A., and Pasini, D., 2012, "Stiffness and strength of tridimensional periodic lattices," Computer Methods in Applied Mechanics and Engineering, 229, pp. 27 43. doi: 10.1016/j.cma.2012.03.018

[84] Vigliotti, A., Deshpande, V. S., and Pasini, D., 2014, "Non linear constitutive models for lattice materials," Journal of the Mechanics and Physics of Solids, 64, pp. 44-60. doi: 10.1016/j.jmps.2013.10.015

[85] Park, S. I., Rosen, D. W., Choi, S. K., and Duty, C. E., 2014, "Effective mechanical properties of lattice material fabricated by material extrusion additive manufacturing," Additive Manufacturing, 1, pp. 12-23. doi: 10.1016/j.addma.2014.07.002

[86] Andreassen, E., and Andreasen, C. S., 2014, "How to determine composite material properties using numerical homogenization," Computational Materials Science, 83, pp. 488-495. doi: 10.1016/j.commatsci.2013.09.006

[87] Dirrenberger, J., Forest, S., Jeulin, D., and Colin, C., "Homogenization of periodic auxetic materials," Proc. Procedia Engineering, pp. 1847-1852. doi: 10.1016/j.proeng.2011.04.307 
[88] van Dijk, N. P., 2016, "Formulation and implementation of stress-driven and/or strain-driven computational homogenization for finite strain," International Journal for Numerical Methods in Engineering, 107(12), pp. 1009-1028. doi: $10.1002 /$ nme. 5198

[89] Schwerdtfeger, J., Schury, F., Stingl, M., Wein, F., Singer, R. F., and Körner, C., 2012, "Mechanical characterisation of a periodic auxetic structure produced by SEBM," Physica Status Solidi (B) Basic Research, 249(7), pp. 1347-1352. doi: 10.1002/pssb.201084211

[90] Zhu, H. X., Hobdell, J. R., and Windle, A. H., 2000, "Effects of cell irregularity on the elastic properties of open-cell foams," Acta Materialia, 48(20), pp. 4893-4900. doi: http://dx.doi.org/10.1016/S1359-6454(00)00282-2

[91] Zhu, H. X., Hobdell, J. R., and Windle, A. H., 2001, "Effects of cell irregularity on the elastic properties of 2D Voronoi honeycombs," Journal of the Mechanics and Physics of Solids, 49(4), pp. 857-870. doi: http://dx.doi.org/10.1016/S00225096(00)00046-6

[92] Zhou, J., Shrotriya, P., and Soboyejo, W. O., 2004, "On the deformation of aluminum lattice block structures: from struts to structures," Mechanics of Materials, 36(8), pp. 723-737. doi: http://dx.doi.org/10.1016/j.mechmat.2003.08.007

[93] Gan, Y. X., Chen, C., and Shen, Y. P., 2005, "Three-dimensional modeling of the mechanical property of linearly elastic open cell foams," International Journal of Solids and Structures, 42(26), pp. 6628-6642. doi: http://dx.doi.org/10.1016/j.ijsolstr.2005.03.002

[94] Cuan-Urquizo, E., Yang, S., and Bhaskar, A., "Mechanical characterisation of additively manufactured material having lattice microstructure," Proc. IOP Conference Series: Materials Science and Engineering. doi: 10.1088/1757899X/74/1/012004

[95] Alkhader, M., and Vural, M., "Effect of microstructure in cellular solids: Bending vs. stretch dominated topologies," Proc. Proceedings of the 3rd International Conference on Recent Advances in Space Technologies, RAST 2007, pp. 136-143. doi: 10.1109/RAST.2007.4283965

[96] Alkhader, M., and Vural, M., 2008, "Mechanical response of cellular solids: Role of cellular topology and microstructural irregularity," International Journal of Engineering Science, 46(10), pp. 1035-1051. doi: 10.1016/j.ijengsci.2008.03.012

[97] Ahmadi, S. M., Campoli, G., Amin Yavari, S., Sajadi, B., Wauthle, R., Schrooten, J., Weinans, H., and Zadpoor, A. A., 2014, "Mechanical behavior of regular opencell porous biomaterials made of diamond lattice unit cells," Journal of the Mechanical Behavior of Biomedical Materials, 34, pp. 106-115. doi: 10.1016/j.jmbbm.2014.02.003

[98] Aremu, A. O., Maskery, I. A., Tuck, C. J., Ashcroft, I. A., Wildman, R. D., and Hague, R. J. M., "Effects of net and solid skins on self-supporting lattice structures," Proc. Conference Proceedings of the Society for Experimental Mechanics Series, pp. 83-89. doi: 10.1007/978-3-319-22443-5_10

[99] Chantarapanich, N., Puttawibul, P., Sucharitpwatskul, S., Jeamwatthanachai, P., Inglam, S., and Sitthiseripratip, K., 2012, "Scaffold library for tissue engineering: A geometric evaluation," Computational and Mathematical Methods in Medicine, 2012. doi: 10.1155/2012/407805 
[100] Zargarian, A., Esfahanian, M., Kadkhodapour, J., and Ziaei-Rad, S., 2014, "Effect of solid distribution on elastic properties of open-cell cellular solids using numerical and experimental methods," Journal of the Mechanical Behavior of Biomedical Materials, 37, pp. 264-273. doi: http://dx.doi.org/10.1016/j.jmbbm.2014.05.018

[101] Ullah, I., Elambasseril, J., Brandt, M., and Feih, S., 2014, "Performance of bioinspired Kagome truss core structures under compression and shear loading," Composite Structures, 118(1), pp. 294-302. doi: 10.1016/j.compstruct.2014.07.036

[102] Salonitis, K., Chantzis, D., and Kappatos, V., 2016, "A hybrid finite element analysis and evolutionary computation method for the design of lightweight lattice components with optimized strut diameter," International Journal of Advanced Manufacturing Technology, pp. 1-13. doi: 10.1007/s00170-016-9528-x

[103] Huo, J., Dérand, P., Rännar, L. E., Hirsch, J. M., and Gamstedt, E. K., 2015, "Failure location prediction by finite element analysis for an additive manufactured mandible implant," Medical Engineering and Physics, 37(9), pp. 862-869. doi: 10.1016/j.medengphy.2015.06.001

[104] Wettergreen, M. A., Bucklen, B. S., Starly, B., Yuksel, E., Sun, W., and Liebschner, M. A. K., 2005, "Creation of a unit block library of architectures for use in assembled scaffold engineering," Computer-Aided Design, 37(11), pp. 1141-1149. doi: http://dx.doi.org/10.1016/j.cad.2005.02.005

[105] Cahill, S., Lohfeld, S., and McHugh, P., 2009, "Finite element predictions compared to experimental results for the effective modulus of bone tissue engineering scaffolds fabricated by selective laser sintering," Journal of Materials Science: Materials in Medicine, 20(6), pp. 1255-1262. doi: 10.1007/s10856-009-3693-5

[106] Hedayati, R., Sadighi, M., Mohammadi-Aghdam, M., and Zadpoor, A. A., 2016, "Mechanical properties of regular porous biomaterials made from truncated cube repeating unit cells: Analytical solutions and computational models," Materials Science and Engineering C, 60, pp. 163-183. doi: 10.1016/j.msec.2015.11.001

[107] Hedayati, R., Sadighi, M., Mohammadi-Aghdam, M., and Zadpoor, A. A., 2016, "Mechanics of additively manufactured porous biomaterials based on the rhombicuboctahedron unit cell," Journal of the Mechanical Behavior of Biomedical Materials, 53, pp. 272-294. doi: 10.1016/j.jmbbm.2015.07.013

[108] Coelho, P. G., Hollister, S. J., Flanagan, C. L., and Fernandes, P. R., 2016, "Bioresorbable scaffolds for bone tissue engineering: Optimal design, fabrication, mechanical testing and scale-size effects analysis," Medical Engineering and Physics, 37(3), pp. 287-296. doi: 10.1016/j.medengphy.2015.01.004

[109] Yang, L., Harrysson, O., West, H., and Cormier, D., 2015, "Mechanical properties of 3D re-entrant honeycomb auxetic structures realized via additive manufacturing," International Journal of Solids and Structures. doi: 10.1016/j.ijsolstr.2015.05.005

[110] Zargarian, A., Esfahanian, M., Kadkhodapour, J., and Ziaei-Rad, S., 2016, "Numerical simulation of the fatigue behavior of additive manufactured titanium porous lattice structures," Materials Science and Engineering: C, 60, pp. 339-347. doi: http://dx.doi.org/10.1016/j.msec.2015.11.054

[111] Sercombe, T. B., Xu, X., Challis, V. J., Green, R., Yue, S., Zhang, Z., and Lee, P. D., 2015, "Failure modes in high strength and stiffness to weight scaffolds produced by Selective Laser Melting," Materials and Design, 67, pp. 501-508. doi: 10.1016/j.matdes.2014.10.063 
[112] Park, S. I., and Rosen, D. W., 2016, "Quantifying effects of material extrusion additive manufacturing process on mechanical properties of lattice structures using as-fabricated voxel modeling," Additive Manufacturing. doi: 10.1016/j.addma.2016.05.006

[113] Sachdeva, A., Singh, S., and Sharma, V. S., 2013, "Investigating surface roughness of parts produced by SLS process," International Journal of Advanced Manufacturing Technology, 64(9-12), pp. 1505-1516. doi: 10.1007/s00170-0124118-Z

[114] Pupo, Y., Monroy, K. P., and Ciurana, J., 2015, "Influence of process parameters on surface quality of CoCrMo produced by selective laser melting," International Journal of Advanced Manufacturing Technology, 80(5-8), pp. 985-995. doi: 10.1007/s00170-015-7040-3

[115] Everhart, W., Sawyer, E., Neidt, T., Dinardo, J., and Brown, B., 2016, "The effect of surface finish on tensile behavior of additively manufactured tensile bars," Journal of Materials Science, 51(8), pp. 3836-3845. doi: 10.1007/s10853-015-97029

[116] Shanjani, Y., Hu, Y., Pilliar, R. M., and Toyserkani, E., 2011, "Mechanical characteristics of solid-freeform-fabricated porous calcium polyphosphate structures with oriented stacked layers," Acta Biomaterialia, 7(4), pp. 1788-1796. doi: 10.1016/j.actbio.2010.12.017

[117] Ladani, L., Razmi, J., and Choudhury, S. F., 2014, "Mechanical anisotropy and strain rate dependency behavior of Ti6Al4V produced using E-beam additive fabrication," Journal of Engineering Materials and Technology, Transactions of the ASME, 136(3). doi: 10.1115/1.4027729

[118] Sridharan, N., Gussev, M., Seibert, R., Parish, C., Norfolk, M., Terrani, K., and Babu, S. S., 2016, "Rationalization of anisotropic mechanical properties of Al-6061 fabricated using ultrasonic additive manufacturing," Acta Materialia, 117, pp. 228237. doi: 10.1016/j.actamat.2016.06.048

[119] Ahn, S. H., Montero, M., Odell, D., Roundy, S., and Wright, P. K., 2002, "Anisotropic material properties of fused deposition modeling ABS," Rapid Prototyping Journal, 8(4), pp. 248-257. doi: 10.1108/13552540210441166

[120] Hambali, R. H., Smith, P., and Rennie, A. E. W., 2012, "Determination of the effect of part orientation to the strength value on additive manufacturing FDM for end-use parts by physical testing and validation via three-dimensional finite element analysis," International Journal of Materials Engineering Innovation, 3(3-4), pp. 269-281. doi: 10.1504/IJMATEI.2012.049266

[121] Ogden, S., and Kessler, S., "Anisotropic finite element modeling of the fused deposition modeling process," Proc. TMS Annual Meeting, pp. 235-246. doi: 10.1002/9781118888056.ch28

[122] Carroll, B. E., Palmer, T. A., and Beese, A. M., 2015, "Anisotropic tensile behavior of Ti-6Al-4V components fabricated with directed energy deposition additive manufacturing," Acta Materialia, 87, pp. 309-320. doi: 10.1016/j.actamat.2014.12.054

[123] Åkerfeldt, P., Antti, M. L., and Pederson, R., 2016, "Influence of microstructure on mechanical properties of laser metal wire-deposited Ti-6Al-4V," Materials Science and Engineering A, 674, pp. 428-437. doi: 10.1016/j.msea.2016.07.038 
[124] Zhang, Q., Chen, J., Zhao, Z., Tan, H., Lin, X., and Huang, W., 2016, "Microstructure and anisotropic tensile behavior of laser additive manufactured TC21 titanium alloy," Materials Science and Engineering A, 673, pp. 204-212. doi: 10.1016/j.msea.2016.07.040

[125] Wauthle, R., Vrancken, B., Beynaerts, B., Jorissen, K., Schrooten, J., Kruth, J. P., and Van Humbeeck, J., 2015, "Effects of build orientation and heat treatment on the microstructure and mechanical properties of selective laser melted Ti6Al4V lattice structures," Additive Manufacturing, 5, pp. 77-84. doi: 10.1016/j.addma.2014.12.008

[126] Reinhart, G., Teufelhart, S., and Riss, F., 2012, "Investigation of the GeometryDependent Anisotropic Material Behavior of Filigree Struts in ALM-Produced Lattice Structures," Physics Procedia, 39, pp. 471-479. doi: http://dx.doi.org/10.1016/j.phpro.2012.10.063

[127] List, F. A., Dehoff, R. R., Lowe, L. E., and Sames, W. J., 2014, "Properties of Inconel 625 mesh structures grown by electron beam additive manufacturing," Materials Science and Engineering A, 615, pp. 191-197. doi: 10.1016/j.msea.2014.07.051

[128] Galeta, T., Raos, P., and Somolanji, M., 2012, "Impact of structure and building orientation on strentgh of 3D printed models," KGK Kautschuk Gummi Kunststoffe, 65(10), pp. 36-42. doi:

[129] Castilho, M., Dias, M., Gbureck, U., Groll, J., Fernandes, P., Pires, I., Gouveia, B., Rodrigues, J., and Vorndran, E., 2013, "Fabrication of computationally designed scaffolds by low temperature 3D printing," Biofabrication, 5(3). doi: 10.1088/17585082/5/3/035012

[130] Zhang, P., and To, A. C., 2016, "Transversely isotropic hyperelastic-viscoplastic model for glassy polymers with application to additive manufactured photopolymers," International Journal of Plasticity, 80, pp. 56-74. doi: 10.1016/j.ijplas.2015.12.012 


\section{List of Figures}

Figure 1. Examples of different types of lattice structures based on the degree of order, (a) Disordered lattice structures, (b) Periodic lattice structures, (c) Conformal lattice

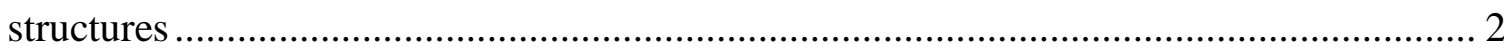

Figure 2. The concept of modeling of lattice structures for AM process .......................... 6

Figure 3. (a) FE model with beam elements, (b) Homogenized FE model with solid

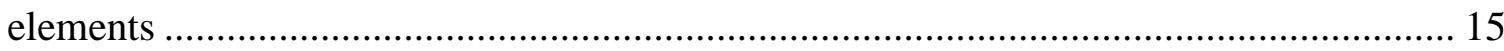

Figure 4. (a) the conceptual configuration semi-joint frame element (b) the as-fabricated

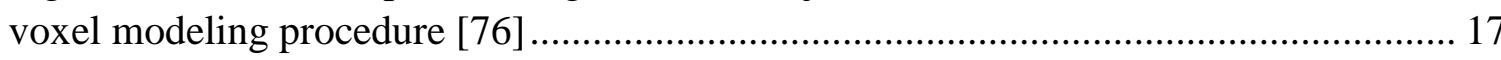

Figure 5. 3D tetrahedral elements compared with beam elements, (a) 3D solid mesh using 19830 elements and 2h 44mins computational time, (b) 1D beam mesh using 160 elements and 51s computational time, (c) 1D beam mesh using 96 elements and 12s

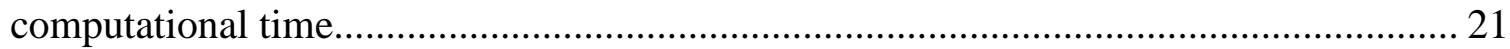

Figure 6. Hybrid FE model to analysis the lattice structure connected to solid materials 24 Figure 7. Contour plot of von Mises stress distribution (MPa) for two scaffolds with exactly the same porosity that were compressed in the y direction, (a) smooth surface, (b)

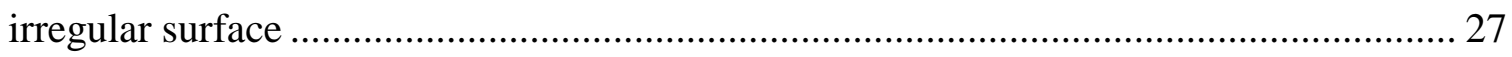

Figure 8. Beam elements with varied diameters to model the irregular strut, (a) implementation in FE model, (b) actual irregularity

Figure 9. Young's modulus and tensile strength as a function of polar angle and strut diameter. 


\section{List of Table}

Table 1a A summary of compressive elastic modulus of lattice structures obtained from experiments ................................................................................................. 10 Table 1b A summary of compressive elastic modulus of lattice structures obtained from

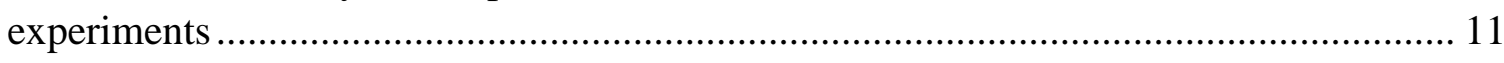

Table 2 Advantages and disadvantages of experimental and simulation methods .......... 21

Table 3 Manufacturing influence considered in the simulation process......................... 29 